\title{
EXPERIMENTAL INVESTIGATION INTO THE CAPACITY OF COLD-FORMED SCREWED STEEL STRAP BRACING CONNECTIONS
}

\author{
M. Zeynalian ${ }^{1, *}$, A. Shelley ${ }^{2}$, H.R. Ronagh ${ }^{3}$ and S. Hatami ${ }^{4}$ \\ ${ }^{1}$ Assistant Professor, Department of Civil Engineering, The University of Isfahan, Iran \\ ${ }^{2}$ Graduated Student, School of Civil Engineering, The University of Queensland, Australia \\ ${ }^{3}$ Professor, Institute for Infrastructure Engineering, Western Sydney University, Sydney, Australia \\ ${ }^{4}$ Assistant Professor, Department of Civil Engineering, Yasouj University, Iran \\ *(Corresponding author: Email: m.zeynalian@eng.ui.ac.ir)
}

Received: 4 July 2017; Revised: 10 July 2017; Accepted: 19 October 2017

\begin{abstract}
An experimental study on the behavior of cold formed steel (CFS) strap bracing connections is presented in this paper. 75 cold-formed steel strap bracing connections were examined. The connections maximum load capacity and the load-deformation behavior as well as the failure modes of the connections are investigated. The strap bracing connections included $0.55 \mathrm{~mm}$ and $0.75 \mathrm{~mm}$ cold-formed G550 steel and four different types of steel strap material. The connections behaviors are discussed and the design capacities calculated from different CFS design standards are compared to the experimental results of the connections. The results show that generally the monotonic tested connections capacities are lower than the cyclic capacities. Also, it is found that although the design provisions predict some of the behaviours of screwed connections, they are not fully suited to accurately predicting the ultimate behaviour of the strap bracing connections. Therefore, the recommended capacities for the strap bracing connections are based on the experimental results.
\end{abstract}

Keywords: Cold formed steel, strap bracing, connection, experimental study, screw

DOI: 10.18057/IJASC.2018.14.4.3

\section{INTRODUCTION}

The application of cold formed steel (CFS) in residential framing construction has become increasingly popular in housing industry in recent decades; and is now a highly competitive alternative to traditional framing due to its unique advantages such as being cost-effective, light-weight, and easy to work with. In order to design CFS structural system accurately, precise estimation of the potential failure modes and associated collapse load capacity is required. One of the most common CFS lateral resisting systems is X strap bracing (Kim et al. [1], Moghimi and Ronagh [2], Zeynalian and Ronagh [3-4]). In this system, straps are connected to the four exterior corners of the walls like an X, often with self-drilling metal screws.

Basically, connections are important components of any structure and are designed more conservatively than members. This is because usually the complexity of connections is more than members to analyze and design; and there are some discrepancies between analysis and actual behavior. In addition, in case of overloading, it is desirable to collapse an individual member rather than in connections, which may affect many members. Thus, improvement of the framing connections would increase the reliability of the structural performance of CFS framing system. This research study is aimed to conduct comparative evaluations for the optimization of one of the most currently in use screwed strap bracing connections in CFS housing industry as shown in Figure 1. 


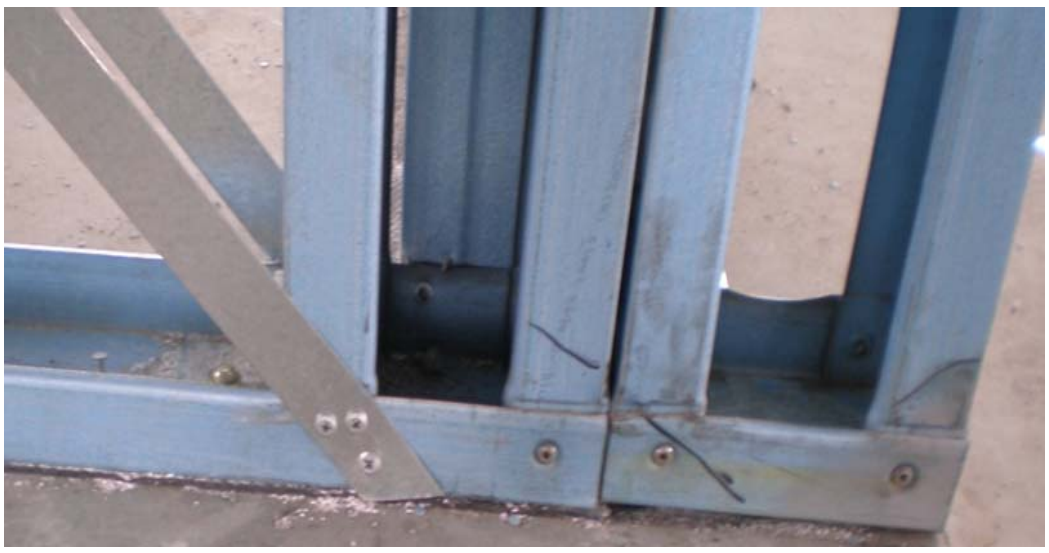

Figure 1. Screwed Strap Bracing to Wall Framing Connection

Four different strap materials were investigated in order to evaluate the number of screws required to obtain the maximum capacity of the connection. The capacities of the strap bracing connections given in this paper are based on the maximum, yield, and ultimate strengths found by analysis of the experimental data.

\section{Failure Modes of Cold Formed Steel Connections}

The screwed connections can fail in one mode or a combination of several modes (Yu and LaBoube [5]) and that these modes are typically edge tearing, bearing, tilting, pull-out, pull-over or by shear failure of the screw itself. Edge tearing occurs in screwed connections when the edge distance or spacing is too small. The tear starts from a screw hole and tears to the edge of the plate or to an adjacent screw hole. Hancock et al. [6] suggest that when the edge and spacing distances are large enough to avoid tear-out failure, bearing failure of the sheet could occur. Bearing failure often produces stretching of the hole on one side of the screw, while the sheet material is bunched together on the other side of the screw. Tilting failure usually occurs when two materials of the same thickness are connected, or when the thicker material is against the screw head. As the two sheets move over each other the screws can become tilted, and when the tilting angle becomes large, pull-out failure can occur. This type of failure is illustrated by Hancock [7] as shown in Figure 2.

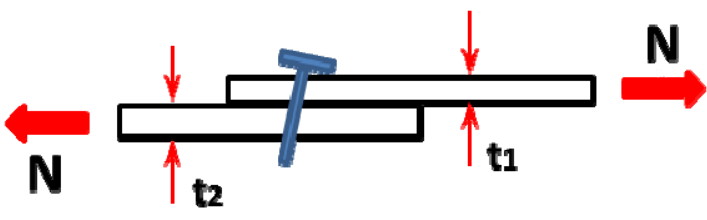

Figure 2. Tilting Failure of Screwed Connections (Hancock [7])

Pull-out failure involves the screw(s) being 'pulled out' of the supporting sheet material under load, as a result of the axial tensile forces in the screws due to the rotated position of the screws relative to the direction of load in the connection (Rogers and Hancock [8]). This type of failure is often associated with tilting failure. Pull-over failure involves the connected sheet 'pulling over' the screw head. Pull-over is enhanced by cyclic loading conditions experienced in high wind areas and/or during seismic activity as this can reduce the tensile strength of the sheet.

Yielding of the gross cross-section of the sheet occurs when $A_{n f} f_{u}>A_{g} f_{y}$, where $A_{n}=$ net area of the cross section, $f_{u}=$ ultimate strength of the sheet, $A_{g}=$ gross area of the cross section, and $f_{y}=$ yield 
strength of the sheet (AS/NZS4600 [9]). This type of failure is ductile and can exhibit large deformations before ultimate failure of a sheet occurs. This ductile behavior is desirable in bracing systems in particular, where sudden brittle failure could be result in catastrophic failure of the overall structure. In contrast to gross cross-section failure, net section failure occurs when $\mathrm{Anfu}_{\mathrm{u}}<\mathrm{Agfy}_{\mathrm{g}}$, and failure is brittle. This type of failure can occur at lower loads than yielding of the gross cross section when the net area of the sheet is reduced by perforations or fastener holes. Screw shear failure occurs by shearing of the screw as the two sheets are pulled over each other. This failure is brittle, and can be catastrophic. Therefore when designing screwed connections it is desirable for one or more of the previously described failure modes to be more probable than screw shear.

\section{Literature Review}

Adham et al [10] tested six full-scale 2.4 x 2.4 m CFS strap shear walls under cyclic loads. They concluded that, upon preventing the buckling and connection failure at the design stage, the system will work more effectively in dissipating energy during the lateral cyclic displacement. Hatami et al. [11] investigated the performance of different strap bracing arrangements in CFS shear walls by means of cyclic loading of a total of ten full-scale walls. They assessed the failure modes of each system and the main factors contributing to the ductile response of the CFS walls to ensure that the diagonal straps yield and respond plastically with a significant drift. Fiorina et al. [12] conducted an experimental study on screw connections between wood and gypsum sheets and cold-formed steel stud profiles. They concluded that the sheathing type has a significant effect on the connections shear response. They also claimed that the connection test results yield reasonable prediction of the lateral response of steel shear walls. Rogers and Hancock [8] investigated the behavior of single overlap screwed specimens and also evaluated the existing design provisions with regard to the accuracy of the provisions in predicting both the capacity and failure mode of these connections. They found that none of their specimens failed in pure bending or tilting, but rather they all experienced a combination of the two modes. They stated that these combinations of failures were due to the very thin sheets used, and for some specimens the use of screws for which did not have thread which extended to the screw head. They found that when the thinner sheet is against the screw head, bearing failure becomes more likely. Lennon et al. [13] reported on a comparative investigation into the shear behavior of some mechanical connections in CFS frames. Five different mechanical fasteners were considered, including self-tapping screws which showed a low initial stiffness. They reported that the ductility of all screws samples tested was high because of the parent metal dragging on the screw threads in the large displacement range of response. Peterman et al. [14] reported an experimental study on hysteretic behavior of the screwed connection between CFS studs and sheathing subject to in-plane lateral demands. They reported that the connections have an important role for energy dissipation in wood sheathed CFS walls. They highlighted that the steel thickness impacts not only shear strength and stiffness, but also failure mode, ranging from highly ductile response to fastener shear.

The findings of the above review have provided indications of failure behaviors exhibited by test specimens and some of the factors which affect these behaviors. There are also criticisms on the strengths and weaknesses of the current design standards. The findings of this literature review will be taken into consideration when the results of the experimentation conducted for this research are evaluated. 


\section{Strap Bracing Connections}

In strap braced CFS buildings, it is common to brace the wall framing with cross bracing at specified intervals throughout the buildings. These cross braces are constructed from steel strap and are connected to the wall framing systems generally using 10-16 wafer head screws (Buildex Co. [15]) which is shown in Figure 3. The currently in use strap bracing arrangement is shown in Figure 4 (Quickframe steel frames Pty Ltd. [16]).
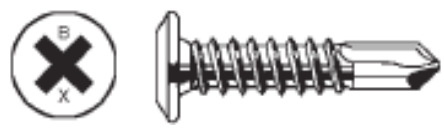

Figure 3. Wafer Head Screw

This study is aimed to investigate the connection arrangement of screws required to adequately secure four different types of strap bracing to wall framing, and the capacities of these connections.
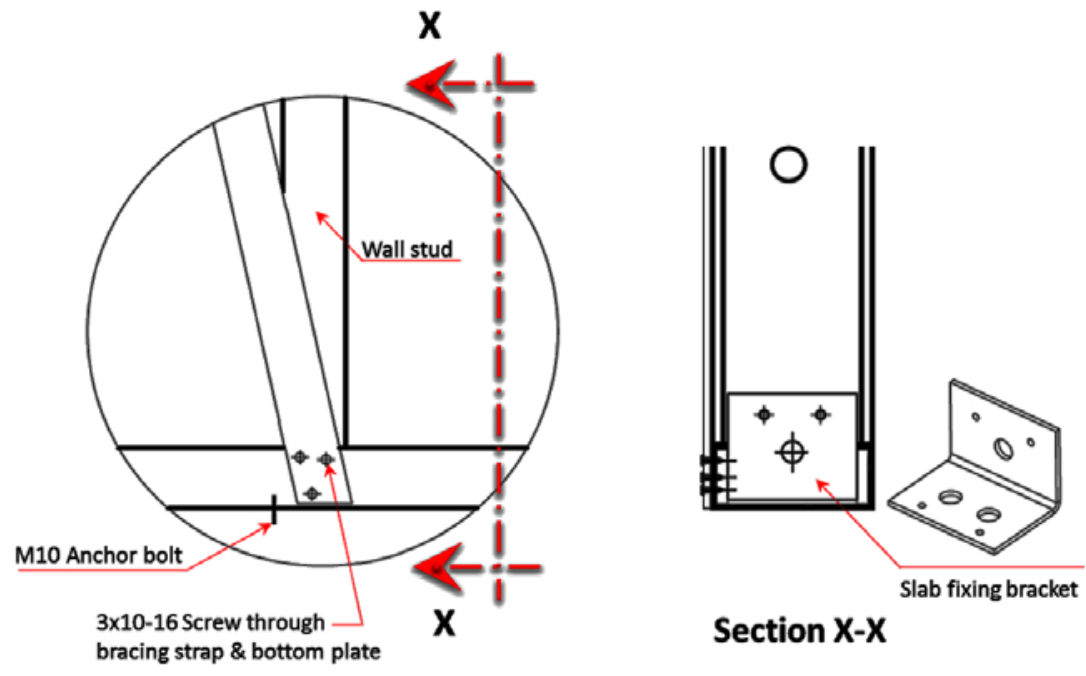

Figure 4. Strap Bracing Detail

The capacity of the connections can limit the ultimate capacity of the overall strap bracing system, particularly in the cases where the limiting failure occurs at the connection. The characteristic yield and ultimate strengths of a strap material determine the maximum potential capacity of the bracing system in which the strap is used; however when the capacity of the strap connection is lower than the ultimate strength of the strap, the connection reduces the ultimate strength of the overall bracing system and therefore reduces the amount of ductility that can occur before ultimate failure of the system occurs.

Strap bracing is designed to carry tensile loading only, so all specimens were tested in tension only. As cyclic loading is an important consideration in designing strap bracing, due to the nature of the lateral loads to which it can be subjected particularly during cyclonic and/or seismic activity, cyclic tests were conducted in addition to monotonic tests of each different specimen type. Hence, it was planned to examine the required screw arrangement to secure the different types of strap through a reliable series of experimental tests. Then, the results of the experimentation were discussed and compared with the design capacities calculated based on the cold-formed steel design guides and standards. 


\subsection{Materials}

Two different most common in use thicknesses of G550 CFS sections for the connection tests were taken into account. The two material thicknesses are $0.55 \mathrm{~mm}$ and $0.75 \mathrm{~mm}$, and will be referred to as types A and B, respectively. The material properties are given in Table 1. Also, four types of steel strap bracing material were considered in this research study (BlueScope Co. [17]). These materials were chosen, as they are materials which they either currently use or would consider using for the strap bracing. Axial tension tests were conducted on specimens of each type of strap to find out the mechanical characteristics of the straps as presented in Table 2. It is necessary to mention that G2 and G3 is represent the steel properties which are illustrated in Table 2 (BlueScope Co. [17]).

Table 1. G550 CFS Properties

\begin{tabular}{|c|c|c|c|c|c|c|}
\hline $\begin{array}{c}\text { Nominal } \\
\text { Grade }(\mathrm{MPa})\end{array}$ & $\begin{array}{c}\text { Elastic Modulus } \\
(\mathrm{GPa})\end{array}$ & $\begin{array}{c}\text { Yield } \\
\text { Stress }\left(\mathrm{f}_{\mathrm{y}}\right) \\
(\mathrm{MPa})\end{array}$ & $\begin{array}{c}\text { Yield } \\
\text { Strain } \\
(\%)\end{array}$ & $\begin{array}{c}\text { Ultimate } \\
\text { Stress } \\
\left(\mathrm{f}_{\mathrm{u}}\right)(\mathrm{MPa})\end{array}$ & $\begin{array}{c}\text { Ultimate } \\
\text { Strain } \\
(\%)\end{array}$ & $\mathrm{f}_{\mathrm{u}} / \mathrm{f}_{\mathrm{y}}$ \\
\hline 550 & 168.93 & 592.26 & 0.45 & 617.25 & 2.86 & 1.04 \\
\hline
\end{tabular}

Table 2. Strap Bracing Material Properties

\begin{tabular}{|c|c|c|c|c|c|c|c|c|c|}
\hline $\begin{array}{c}\text { Strap } \\
\text { Numbe } \\
\mathrm{r}\end{array}$ & $\begin{array}{c}\text { Description/Nominal } \\
\text { Dimensions (mm*mm) } \\
{[17]}\end{array}$ & $\begin{array}{c}\text { Actual } \\
\text { Width } \\
(\mathrm{mm})\end{array}$ & $\begin{array}{c}\text { Actual } \\
\text { Thickness } \\
(\mathrm{mm})\end{array}$ & $\begin{array}{c}\text { Elastic } \\
\text { Modulus } \\
(\mathrm{GPa})\end{array}$ & $\begin{array}{c}\text { Yield } \\
\text { Stress } \\
\left(\mathrm{f}_{\mathrm{y}}\right) \\
(\mathrm{MPa})\end{array}$ & $\begin{array}{c}\text { Yield } \\
\text { Elongatio } \\
\mathrm{n}(\%)\end{array}$ & $\begin{array}{c}\text { Ultimate } \\
\text { Stress } \\
\left(\mathrm{f}_{\mathrm{u}}\right) \\
(\mathrm{MPa})\end{array}$ & $\begin{array}{c}\text { Ultimate } \\
\text { Elongatio } \\
\mathrm{n} \\
(\%)\end{array}$ & $\mathrm{f}_{\mathrm{u}} / \mathrm{f}_{\mathrm{y}}$ \\
\hline 1 & Perforated G3 30*0.75 & 29.4 & 0.78 & 154 & 232 & 0.36 & 246 & 1.61 & 1.06 \\
\hline 2 & Solid G2 30*0.75 & 29.5 & 0.83 & 161 & 290 & 0.38 & 293 & 25.2 & 1.01 \\
\hline 3 & Perforated G2 30*0.75 & 29.5 & 0.74 & 133 & 270 & 0.40 & 271 & 4.07 & 1.00 \\
\hline 4 & Solid G2 40*1.0 & 40.1 & 0.96 & 150 & 298 & 0.40 & 302 & 22 & 1.01 \\
\hline
\end{tabular}

Also, the strength property information provided by Buildex Co. [15] for these 10-16 screws is presented in Table 3.

Table 3. Properties for the 10-16 Screw

\begin{tabular}{|c|c|c|c|c|}
\hline Gauge/TPI & $\begin{array}{c}\text { Nominal } \\
\text { Diameter }\end{array}$ & $\begin{array}{c}\text { Head } \\
\text { Diameter }\end{array}$ & $\begin{array}{c}\text { Single Shear } \\
\text { Strength }\end{array}$ & $\begin{array}{c}\text { Axial } \\
\text { Tensile } \\
\text { Strength }\end{array}$ \\
\hline $10-16$ & $4.8 \mathrm{~mm}$ & $9 \mathrm{~mm}$ & $5.2 \mathrm{kN}$ & $8.2 \mathrm{kN}$ \\
\hline
\end{tabular}

\subsection{Screw Arrangements}

The capacity of one screw was tested first with the type 2 solid strap. This estimate of the capacity of about $2.5 \mathrm{kN}$ per screw was then used to estimate the required number of screws for each strap. The nominal tension capacity of each strap bracing material was determined using Australian steel structures standard (AS/NZS4100 [18]) which deems that the nominal section capacity should be taken to be the lesser of $N_{t}=A_{g} f_{y}$; and $N_{t}=0.85 k_{t} A_{n} f_{u}$ where $N_{t}$ is the nominal section capacity in tension, $A_{g}$ represents the gross area of the cross-section, $f_{y}$ is the yield stress used in design, $k_{t}=$ the correction factor, $A_{n}=$ the net are of the strap and, and $f_{u}$ is the ultimate stress. The nominal section capacity was then divided by the capacity per screw to estimate the number of screws required to prevent pull-out and obtain the maximum possible capacity of the strap bracing.

The optimal screw arrangements were based on two criteria. The first criterion was that the arrangement must conform to the spacing requirements of standard AS/NZS4600 [9]. The second criterion was that the arrangement should maximize the minimum net area for the possible failures that can occur through the holes in the strap. The second criterion was the reason for placing 2 
individual screws along the strap before placing 2 screws together in a line perpendicular to the line of force as could be seen for the arrangements for more than 3 screws in the type 2 and 4 solid straps as illustrated in Figures 5 and 6, respectively; the net area at the connection could not be increased above the net area when failure occurs through only a single screw, and therefore this design was sufficient. LaBoube and Sokol [19] proved that the pattern of screws used has a very limited impact on the strength of a connection and therefore for this study more detailed connection design was not considered necessary.

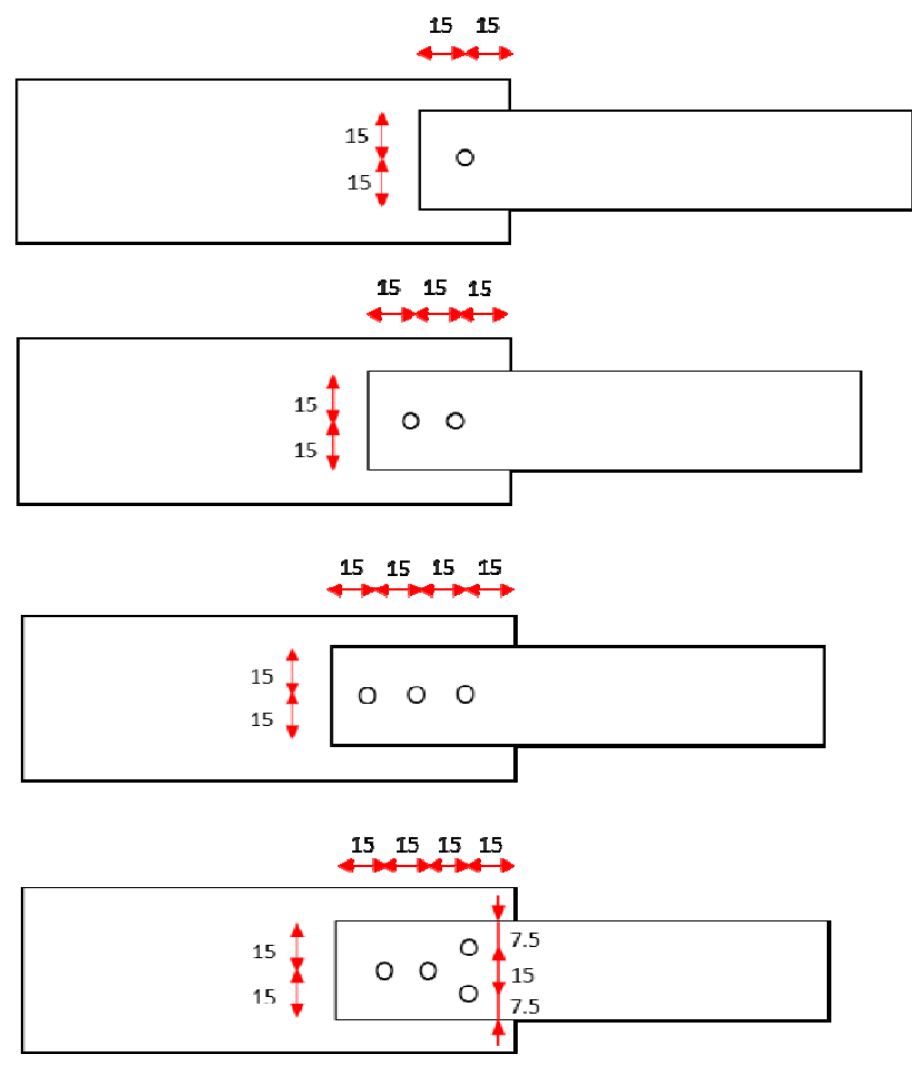

Figure 5. Screw Arrangements for Solid Type 2 Strap (All Dimensions are in mm)

The perforated straps were fastened using existing perforations where more than 1 screw was used in a connection. The end distance in the line of force from the center of the screw to the edge of the strap was always at least the $3 \mathrm{~d}_{\mathrm{f}}$ (diameter of screw) required by AS/NZS4600; however the spacing of screws and perpendicular edge distance was governed by the existing perforations. If the existing holes were not used, additional holes would have reduced the net section which would have weakened the connection more than if the existing $3 \mathrm{~mm}$ holes were increased to $4.8 \mathrm{~mm}$ holes by the screws. The patterns of the perforations in strap types 1 and 3 were the same and were illustrated in Figure 7. 

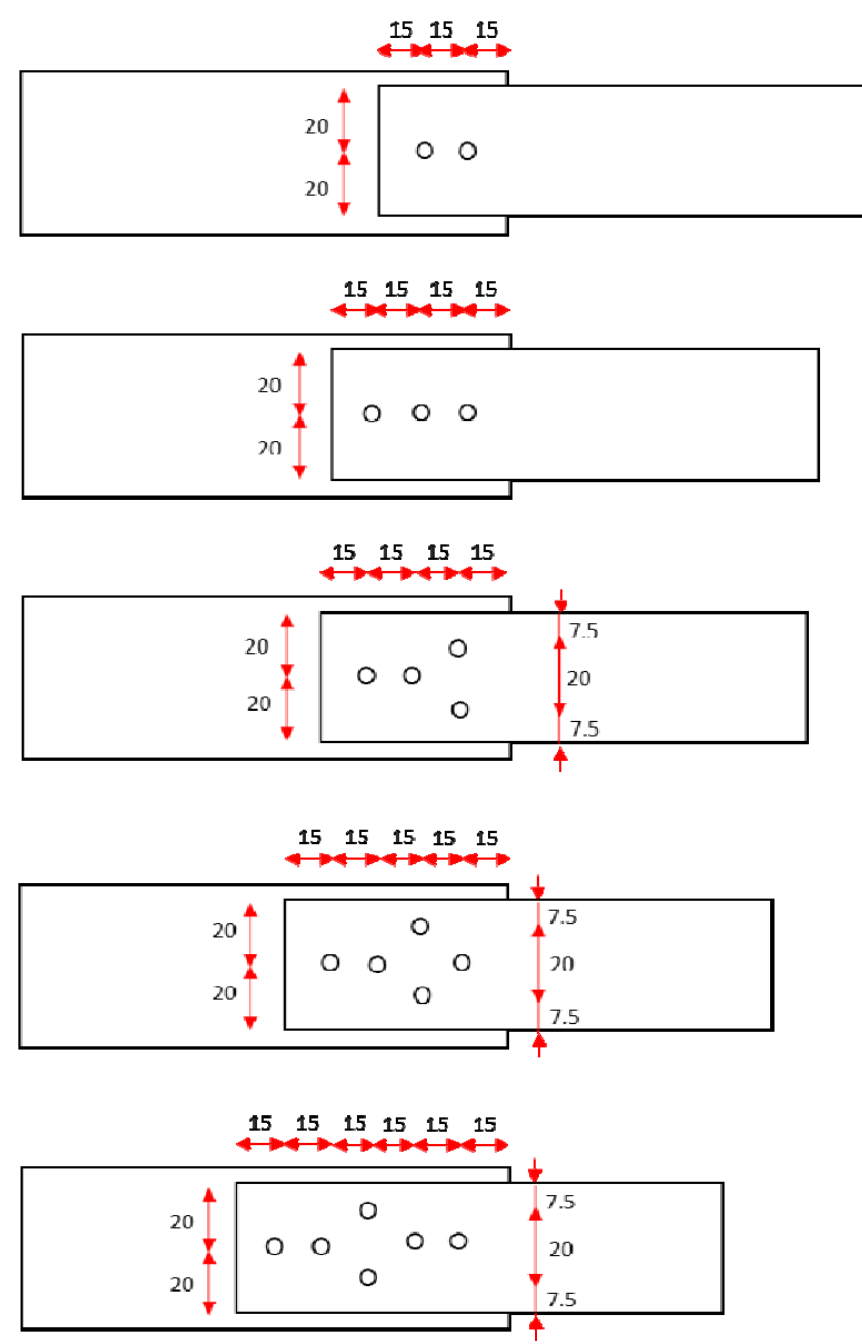

Figure 6. Screw Arrangements for Solid Type 4 Strap (All Dimensions are in mm)

\begin{tabular}{lllllllll}
\hline & 0 & 0 & 0 & 0 & 0 & 0 & 0 & 0 \\
0 & 0 & 0 & & 0 & 0 \\
\hline
\end{tabular}

Figure 7. Perforations in Strap Types 1 and 3

\section{EXPERIMENTAL PROGRAM}

The program consisted of 75 specimens to investigate the structural performance of strap bracing connections. It is necessary to mention that this study is part of a major research project (Zeynalian and Ronagh [20], Zeynalian et al. [21]) that is concerned with structural performance of different currently in-use CFS structures. These specimens were tested in the structural laboratory of the School of Civil Engineering, the University of Queensland. 


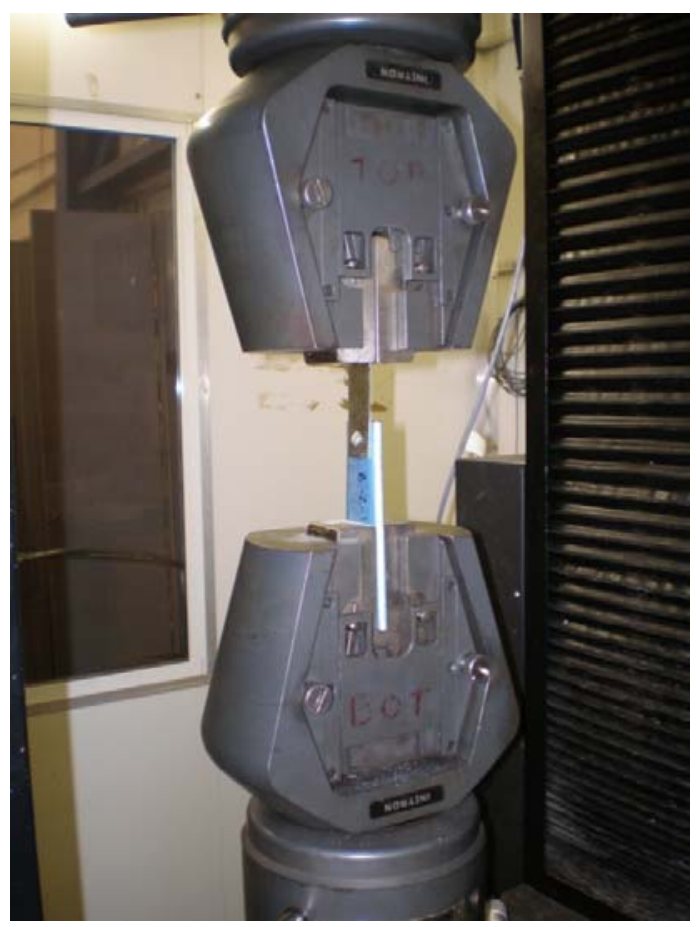

Figure 8. Testing Machine Set-up

The specimens were held in the grips of the testing machine at two ends: one of cold-formed steel, and the other of strap bracing. It worth to note that for specimen preparation, first, the flanges of the cold-formed steel C-section were cut into pieces of approximately $150 \mathrm{~mm}$ in length. Then, the strap bracing materials were cut into lengths of approximately $150 \mathrm{~mm}$. After that, the screws were fastened in the chosen arrangements according to the currently in use fixing recommendations using a power screwdriver; and finally, the specimens were tightened into grips of the machine at both ends. The overall length of the specimen between the grips was $150 \mathrm{~mm}$. The specimens' name notation is illustrated in Figure 9.

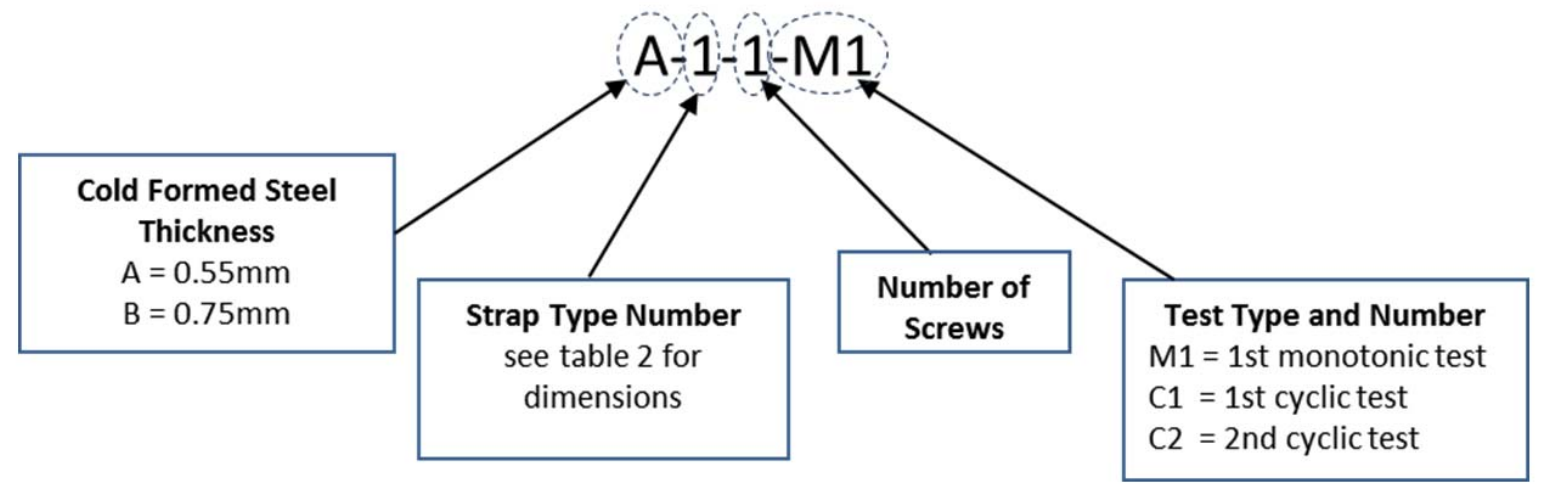

Figure 9. The Specimen Name Notation

Based on the recommendation of the ASTM Standard (ASTM-E2126-07 [22]) detailing test methods for cyclic load tests, one monotonic axial tension test to failure and two cyclic tests were conducted on each different specimen type. In monotonic test, the specimens were loaded to failure at a rate of $10 \mathrm{~mm} / \mathrm{min}$ until failure occurred, whereas in the cyclic tests, a loading regime which is demonstrated in Figure 10, was applied. 


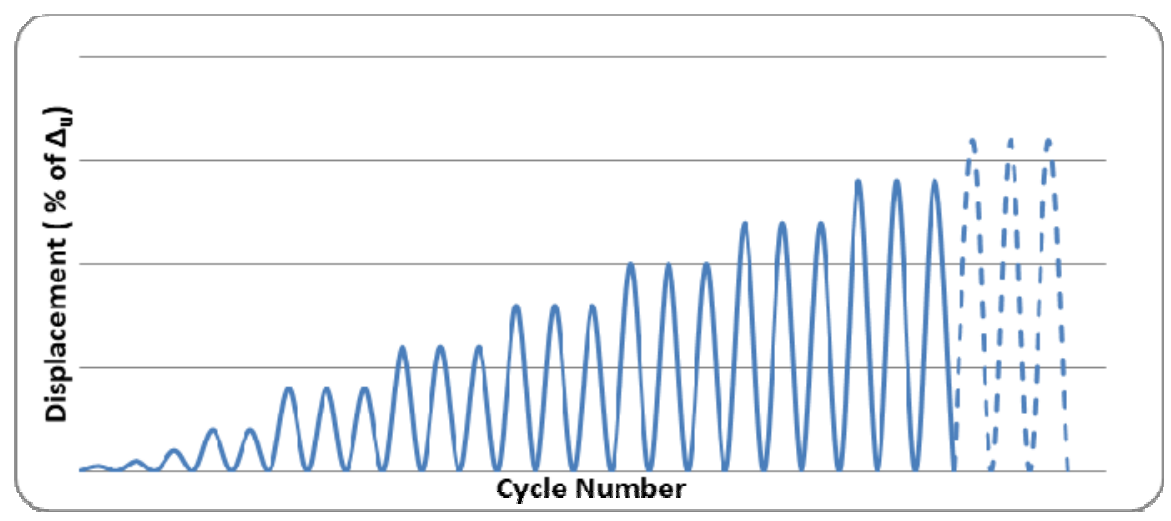

Figure 10. Cyclic Testing Extension Regime (ASTM-E2126-07 [22])

The cyclic loading regime, involved two stages of displacement patterns. The first stage involved single displacement cycles of $2.5 \%, 5 \%$ and $10 \%$, and two cycles of $20 \%$ of the ultimate displacement found in the monotonic test. The second stage involved three cycles each of $20 \%$, $40 \%, 60 \%, 80 \%, 100 \%$, and $120 \%$ of the ultimate displacement until the specimen failed. The rate of extension was varied throughout the cyclic test to suit the capability of the testing machine. For the shorter extensions the rate of loading was between 1 and $10 \mathrm{~mm} / \mathrm{min}$, while the greater extension cycles were conducted at between 15 and $25 \mathrm{~mm} / \mathrm{min}$.

\section{EXPERIMENTAL RESULTS}

A load-extension graph was plotted for each monotonic test specimen in order to find the yield, maximum, and ultimate loads, and their corresponding extensions/displacements. An example of the load-extension graphs is shown in Figure 11. It is necessary to mention that the linear part of the curves is relatively small. That is because the curves represent the load-deformation of the whole connections, including the members and screw. Hence, the graphs imply the screw looseness and sliding as well, which lead to occurrence of nonlinearity in the graphs.

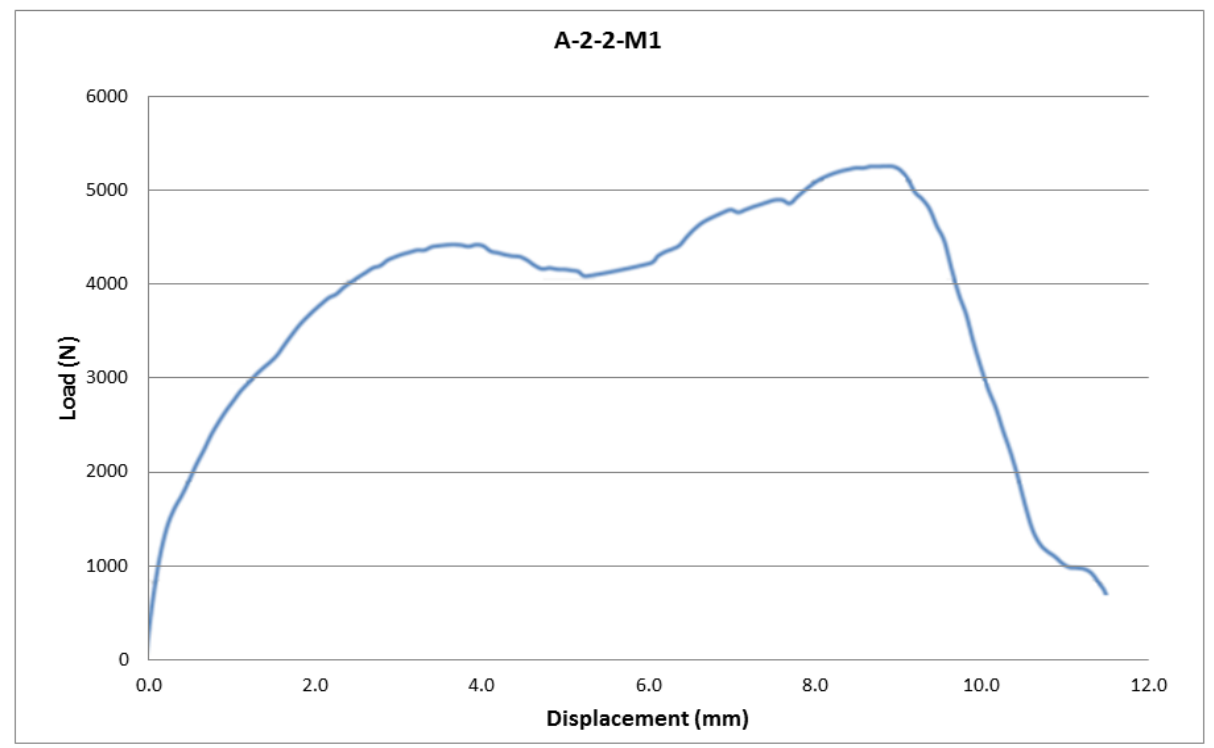

Figure 11. Load-extension Graph from Monotonic Test Results 
The data from the cyclic test specimen results was first graphed in the load-extension form, referred to as a hysteresis curve, and from that curve an envelope curve was plotted by recording the maximum load for the first cycle of each phase of the cyclic loading. Examples of the hysteresis and envelope curves are shown in Figures 12 and 13, respectively.

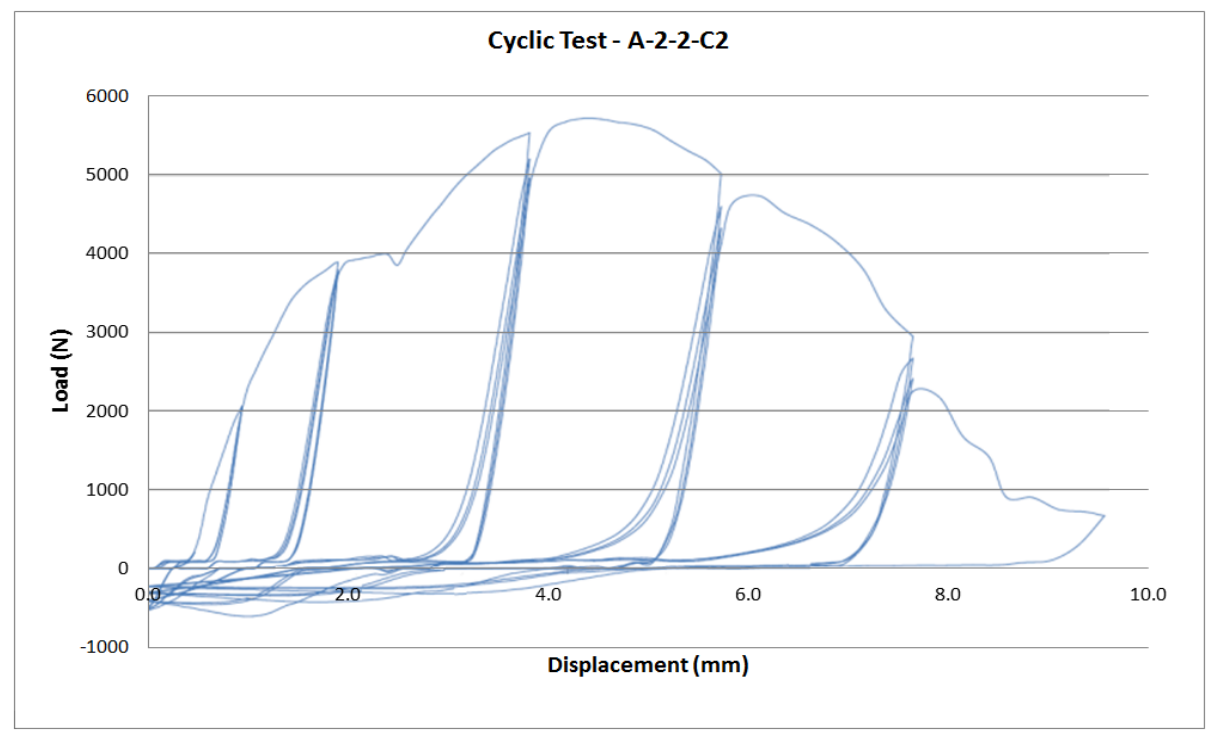

Figure 12. Example of Hysteresis Curve from Cyclic Test

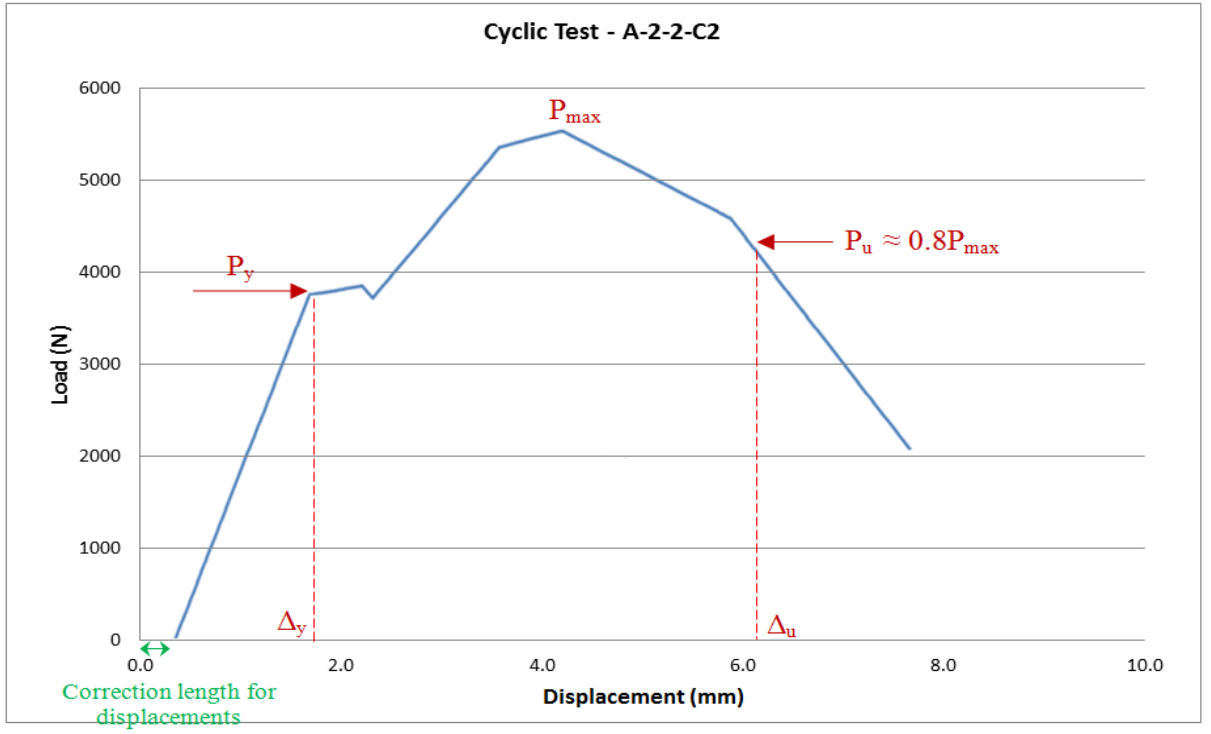

Figure 13. Example of Envelope Curve taken from Hysteresis

It should be mentioned that initially very small amounts of load were taken by the specimen over a certain length of extension. This is a result of the specimen straightening out and adjusting as it takes the load of the machine. To overcome the error which this may have caused in the calculation of the parameters, the extension length before the load on each specimen began to increase was taken away from the measured yield and ultimate displacements. The results of the monotonic and cyclic strap bracing tests are summarized in Tables 4, 5, and 6 on the following pages. The maximum load $\left(\mathrm{P}_{\max }\right)$, yield load $\left(\mathrm{P}_{\mathrm{y}}\right)$, ultimate load $\left(\mathrm{P}_{\mathrm{u}}\right)$, and corresponding displacement at yield $\left(\Delta_{\mathrm{y}}\right)$ and displacement at ultimate load $\left(\Delta_{\mathrm{u}}\right)$ were found from the load-displacement graphs and 
envelope curves for monotonic and cyclic tests respectively. According to ASTM Standard E2126 [22], $\Delta_{\mathrm{u}}$ shall be an estimate of the maximum displacement at which the load in a primary cycle has not yet dropped below $\mathrm{P}_{\mathrm{u}}=0.8 \mathrm{P}_{\max }$ as illustrated in Figure 13 . The ductility factor $\mathrm{R}_{\mu}$, the yielding factor $\mathrm{R}_{\mathrm{f}}$, and the elastic shear stiffness $\mathrm{K}_{\mathrm{e}}$ are also evaluated. The ductility factor is the ratio of displacement at the ultimate load to the displacement at the start of yield. Therefore, as the ductility factor increases, so does the ductile behavior exhibited by a specimen. The yielding factor $\mathrm{R}_{\mathrm{f}}$ which is defined as the ratio of the maximum load $\left(\mathrm{P}_{\max }\right)$ to $\mathrm{Ag}_{\mathrm{g}} \mathrm{F}_{\mathrm{y}}$, indicates whether a specimen should have yielded before the maximum load capacity of the connection was reached. If the yielding factor is less than one, no yielding has place, and in contrast if the yielding factor is above one, the specimen has exhibited yielding. The ASTM Standard E2126 defines the elastic shear stiffness $\mathrm{K}_{\mathrm{e}}$ to be "the resistance to deformation of a connection in the elastic range before the first major event is achieved, which can be expressed as a slope measured by the ratio of resisted shear load to the corresponding displacement'. A major event as referred to by the ASTM Standard as the first limit state to occur, where a limit state is the point where there is a change in the behavior of the system. The limit states for these strap bracing connections are the yield limit state, the strength limit state and the failure limit state.

A discussion on the failure modes and trends exhibited in the monotonic tests and a similar discussion regarding any additional trends from the cyclic test results is presented here. This will be followed by an evaluation of the capacities of each strap to cold-formed steel connection and a comparison of these capacities for the monotonic and cyclic tests. Finally the calculated design capacities will be compared to the actual experimental capacities of the connections. It is necessary to mention that the notations for the failure modes observed during experimentation are:

$$
\begin{aligned}
& \text { - } \mathrm{B}=\text { bearing } \\
& \text { - } \mathrm{T}=\text { tilting } \\
& \text { - } \mathrm{TR}=\text { tear-out } \\
& \text { - } \mathrm{PT}=\text { pull-out } \\
& \text { - } \mathrm{PR}=\text { pull-over } \\
& \text { - } \mathrm{NSF}=\text { net section failure } \\
& \text { - } \quad(\mathrm{m})=\text { moderate }\left(\approx 1-2 \mathrm{~mm} \text { bearing; } \leq 20^{\circ} \text { tilting }\right) \\
& \text { - } \quad(\mathrm{s})=\text { severe }\left(>2 \mathrm{~mm} \text { bearing; }>20^{\circ} \text { tilting }\right)
\end{aligned}
$$

\begin{tabular}{|c|c|c|c|c|c|c|c|c|c|c|c|c|c|c|c|}
\hline & & $\begin{array}{c}\text { Specimen } \\
\text { Name }\end{array}$ & $\begin{array}{l}\mathbf{P}_{\max } \\
(\mathrm{N})\end{array}$ & $\begin{array}{l}\mathbf{P}_{\mathbf{y}} \\
(\mathrm{N})\end{array}$ & $\begin{array}{c}\boldsymbol{\Delta}_{\mathbf{y}} \\
(\mathrm{mm})\end{array}$ & $\begin{array}{c}\mathbf{P}_{\mathbf{u}} \\
(\mathrm{N})\end{array}$ & $\begin{array}{c}\boldsymbol{\Delta}_{\mathbf{u}} \\
(\mathrm{mm})\end{array}$ & $\underset{\left(\mathrm{mm}^{2}\right)}{\mathbf{A g}}$ & $\begin{array}{c}\mathbf{A}_{\mathbf{n}} \\
\left(\mathrm{mm}^{2}\right)\end{array}$ & $\begin{array}{c}\mathbf{A g}_{\mathbf{g}} \mathbf{F}_{\mathbf{y}} \\
(\mathrm{N})\end{array}$ & $\begin{array}{c}0.85 \mathbf{A}_{\mathbf{n}} \cdot \mathbf{F}_{\mathbf{u}} \\
(\mathrm{N})\end{array}$ & $\mathbf{R}_{\mu}$ & $\mathbf{R}_{\mathbf{f}}$ & $\mathbf{K}_{\mathbf{e}}$ & Failure Mode \\
\hline \multirow{13}{*}{$\begin{array}{c}\text { CFS } \\
\text { Type A } \\
0.55 \mathrm{~mm}\end{array}$} & \multirow{3}{*}{$\begin{array}{c}\text { Strap } \\
1\end{array}$} & A-1-1-Ml & 2472 & 2210 & 1.2 & 1980 & 3.1 & 22.9 & 16.2 & 5641.3 & 3199.7 & 2.58 & 0.44 & 3955 & $(\mathrm{~m}) \mathrm{B}+(\mathrm{m}) \mathrm{T}+\mathrm{PT}$ \\
\hline & & A-1-2-M1 & 4781 & 4130 & 3.8 & 3820 & 7.3 & 22.9 & 15.5 & 5641.3 & 3056.4 & 1.92 & 0.85 & 2854 & $(\mathrm{~m}) \mathrm{B}+(\mathrm{s}) \mathrm{T}+\mathrm{PT}$ \\
\hline & & A-1-3-M1 & 6084 & 4830 & 2 & 4860 & 6.9 & 22.9 & 15.5 & 5641.3 & 3056.4 & 3.45 & 1.08 & 9360 & $(\mathrm{~m}) \mathrm{T}+\mathrm{NSF}$ \\
\hline & \multirow{3}{*}{$\begin{array}{c}\text { Strap } \\
3\end{array}$} & A-3-1-M1 & 2666 & 1990 & 1.3 & 2130 & 5.6 & 21.8 & 15.5 & 5915.9 & 3549.8 & 4.31 & 0.45 & 5332 & $(\mathrm{~m}) \mathrm{B}+(\mathrm{s}) \mathrm{T}+\mathrm{PT}$ \\
\hline & & A-3-2-M1 & 4769 & 3140 & 1.8 & 3820 & 6.7 & 21.8 & 15.5 & 5915.9 & 3557.0 & 3.72 & 0.81 & 2935 & $(\mathrm{~m}) \mathrm{B}+(\mathrm{m}) \mathrm{T}+\mathrm{PT}$ \\
\hline & & A-3-3-M1 & 6580 & 4900 & 3.2 & 5260 & 11.6 & 21.8 & 15.5 & 5915.9 & 3557.0 & 3.63 & 1.11 & 3290 & $(\mathrm{~m}) \mathrm{T}+\mathrm{NSF}$ \\
\hline & \multirow{4}{*}{$\begin{array}{c}\text { Strap } \\
2\end{array}$} & A-2-1-M1 & 2820 & 2820 & 2.1 & 2260 & 5 & 24.5 & 20.5 & 7100.7 & 5105.8 & 2.38 & 0.40 & 3760 & $(\mathrm{~s}) \mathrm{B}+(\mathrm{m}) \mathrm{T}+\mathrm{PT}$ \\
\hline & & A-2-2-M1 & 5150 & 4355 & 3.32 & 4120 & 9.1 & 24.5 & 20.5 & 7100.7 & 5105.8 & 2.74 & 0.73 & 4120 & $(\mathrm{~m}) \mathrm{B}+(\mathrm{s}) \mathrm{T}+\mathrm{PT}$ \\
\hline & & A-2-3-M1 & 7000 & 7000 & 4.3 & 5600 & 7.2 & 24.5 & 20.5 & 7100.7 & 5105.8 & 1.67 & 0.99 & 8000 & $(\mathrm{~m}) \mathrm{B}+(\mathrm{s}) \mathrm{T}+\mathrm{PT}$ \\
\hline & & A-2-4-M1 & 7820 & 7226 & 6.15 & 6260 & 17.5 & 24.5 & 20.5 & 7100.7 & 5105.8 & 2.85 & 1.10 & 5586 & NSF \\
\hline & \multirow{3}{*}{$\begin{array}{c}\text { Strap } \\
4\end{array}$} & A-4-4-M1 & 10550 & 7120 & 4.8 & 8440 & 18.6 & 38.5 & 33.9 & 11625.8 & 8584.3 & 3.88 & 0.91 & 4220 & $(\mathrm{~s}) \mathrm{B}+(\mathrm{s}) \mathrm{T}+\mathrm{PT}$ \\
\hline & & A-4-5-M1 & 11570 & 7760 & 5.1 & 9260 & 20.9 & 38.5 & 33.9 & 11625.8 & 8584.3 & 4.10 & 1.00 & 3045 & $(\mathrm{~s}) \mathrm{B}+(\mathrm{s}) \mathrm{T}+\mathrm{PT}$ \\
\hline & & A-4-6-M1 & 13030 & 11090 & 5 & 10430 & 27.9 & 38.5 & 33.9 & 11625.8 & 8584.3 & 5.58 & 1.12 & 6949 & NSF \\
\hline CFS & Strap & B-1-1-Ml & 3801 & 2860 & 2.5 & 3040 & 6.3 & 22.9 & 16.2 & 5641.3 & 3199.7 & 2.52 & 0.67 & 2339 & $(\mathrm{~m}) \mathrm{B}+(\mathrm{s}) \mathrm{T}+\mathrm{PT}$ \\
\hline
\end{tabular}

Table 4. Monotonic Tests Results 


\begin{tabular}{|c|c|c|c|c|c|c|c|c|c|c|c|c|c|c|c|}
\hline \multirow{11}{*}{$\begin{array}{c}\text { Type B } \\
0.75 \mathrm{~mm}\end{array}$} & \multirow[t]{2}{*}{1} & B-1-2-M1 & 6250 & 2750 & 1 & 5000 & 9 & 22.9 & 15.5 & 5641.3 & 3056.4 & 9.00 & 1.11 & 3247 & $(\mathrm{~s}) \mathrm{TR}+(\mathrm{s}) \mathrm{T}+\mathrm{PT}$ \\
\hline & & B-1-3-M1 & 6760 & 5630 & 2.4 & 5410 & 6.9 & 22.9 & 15.5 & 5641.3 & 3056.4 & 2.88 & 1.20 & 6438 & NSF \\
\hline & \multirow{3}{*}{$\begin{array}{c}\text { Strap } \\
\mathbf{3}\end{array}$} & B-3-1-M1 & 3350 & 3070 & 1.5 & 2680 & 6.2 & 21.8 & 15.5 & 5915.9 & 3549.8 & 4.13 & \begin{tabular}{|l|}
0.57 \\
\end{tabular} & 3941 & $(\mathrm{~s}) \mathrm{B}+(\mathrm{s}) \mathrm{T}+\mathrm{PT}$ \\
\hline & & B-3-2-M1 & 6590 & 4240 & 2.6 & 5270 & 10.9 & 21.8 & 15.5 & 5915.9 & 3557.0 & 4.19 & 1.11 & 2897 & $(\mathrm{~s}) \mathrm{TR}+(\mathrm{s}) \mathrm{T}+\mathrm{PT}$ \\
\hline & & B-3-3-M1 & 6800 & 5610 & 2.5 & 5440 & 7.1 & 21.8 & 15.5 & 5915.9 & 3557.0 & 2.84 & 1.15 & 6974 & NSF \\
\hline & \multirow{3}{*}{$\begin{array}{c}\text { Strap } \\
\mathbf{2}\end{array}$} & B-2-1-M1 & 3920 & 3078 & 2.2 & 3130 & 6.6 & 24.5 & 20.5 & 7100.7 & 5105.8 & 3.00 & 0.55 & 3834 & $(\mathrm{~m}) \mathrm{B}+(\mathrm{s}) \mathrm{T}+\mathrm{PT}$ \\
\hline & & B-2-2-M1 & 6280 & 5180 & 1.3 & 5020 & 8.9 & 24.5 & 20. & 7100.7 & 5105.8 & 6.85 & 0.88 & 10253 & $(\mathrm{~m}) \mathrm{B}+(\mathrm{s}) \mathrm{T}+\mathrm{PT}$ \\
\hline & & B-2-3-M1 & 8050 & 7290 & 3.34 & 6440 & 11 & 24.5 & 20.5 & 7100.7 & 5105.8 & 3.29 & 1.13 & 10387 & NSF \\
\hline & \multirow{3}{*}{$\begin{array}{c}\text { Strap } \\
\mathbf{4}\end{array}$} & B-4-2-M1 & 6420 & 3440 & 0.9 & 5140 & 6 & 38.5 & 33.9 & 11625.8 & 8584.3 & 6.67 & 0.55 & 3951 & $(\mathrm{~m}) \mathrm{B}+(\mathrm{m}) \mathrm{T}+\mathrm{PT}$ \\
\hline & & B-4-3-M1 & 9230 & 4810 & 1 & 7380 & 8.9 & 38.5 & 33.9 & 11625.8 & 8584.3 & 8.90 & 0.79 & 11538 & $(\mathrm{~m}) \mathrm{B}+(\mathrm{s}) \mathrm{T}+\mathrm{PT}$ \\
\hline & & B-4-4-M1 & 12670 & 10163 & 1.67 & 10140 & 10.7 & 38.5 & 33.9 & 11625.8 & 8584.3 & 6.41 & 1.09 & 10536 & (m)T+NSF \\
\hline
\end{tabular}

The monotonic test results for all connections show a general trend of increasing capacity with the increasing number of screws. This is a trend which is commonly accepted for screwed connections and has been proven by prior research by LaBoube and Sokol [19]. The contribution of each screw decreased as the number of screws in the connection increased which was also proven in the research by LaBoube and Sokol. For the connection specimens that included fewer screws than were required for the strap to achieve its maximum possible capacity in tension, the modes of failure which were exhibited were combinations of bearing, tilting and pull-out. For each connection between a different strap type and cold-formed steel thickness, at least two connections using the same materials were tested with fewer screws than were required to achieve the maximum strap capacity. These connections were tested to evaluate: the failure modes that occurred when fewer screws were used, and the reduction in capacity as the number of screws is decreased. A load-extension graph from a specimen for which pull-out was the ultimate failure mode is shown in Figure 14. It shows straight that after the maximum load is reached the load begins to drop as the screw pulls out.

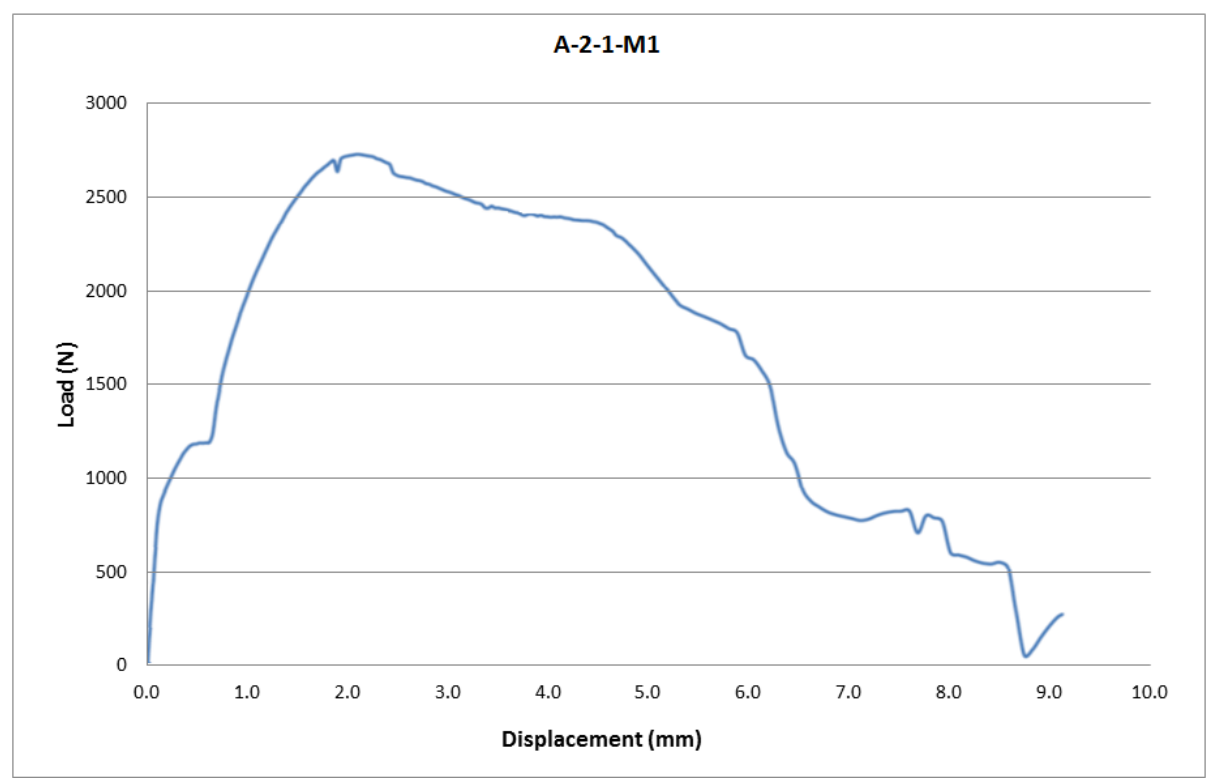

Figure 14. Load-extension Graph for a Pull-out Failure - Solid Strap

Figure 15 shows a load-extension for a perforated strap specimen which failed by pull-out. The initial yielding appears to occur in stages which can be attributed to the strap yielding at the different cross-sections along the strap due to the perforations. The load peaks which occur after the maximum load are due to the threads bearing on the cold-formed steel as they pull out one by one. 


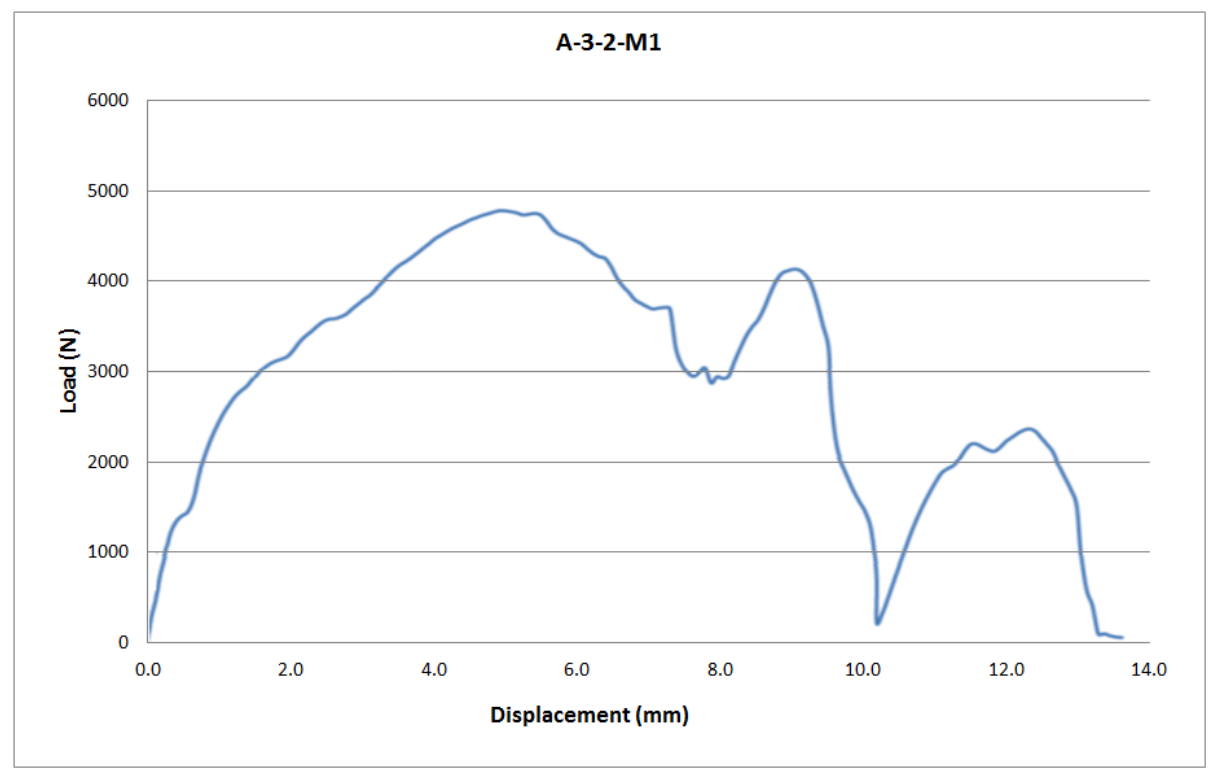

Figure 15. Load-extension Graph Pull-out Failure - Perforated Strap

In contrast to Figure 14 and Figure 15, Figure 16 is a load-extension plot for a specimen which failed by net section failure after yielding and significant ductile behavior had occurred.

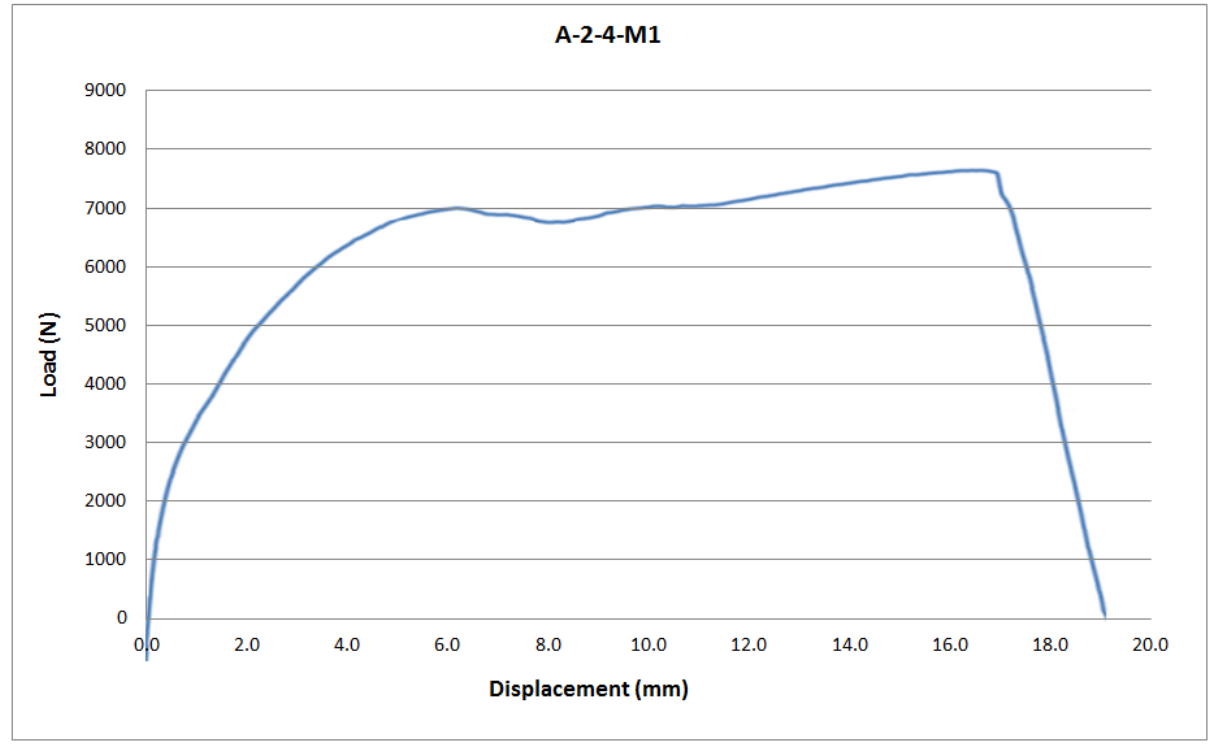

Figure 16. Load-extension Curve for a Net Section Failure - Solid Strap

Some examples of different failure modes that occurred in the tested strap bracing specimens are shown in Figures 17 and 18, respectively, for some different specimens. 


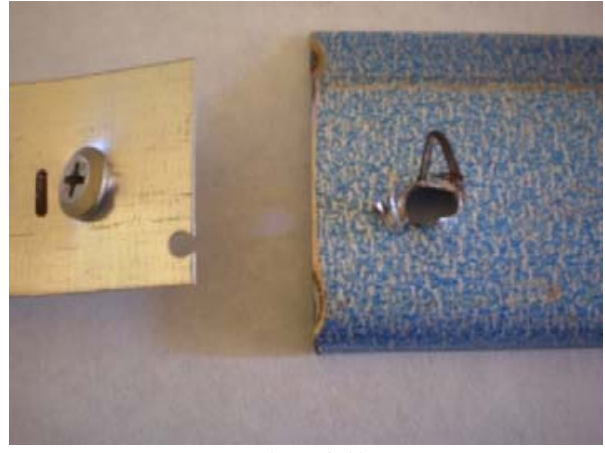

Bearing failure Specimen A-1-1-M1

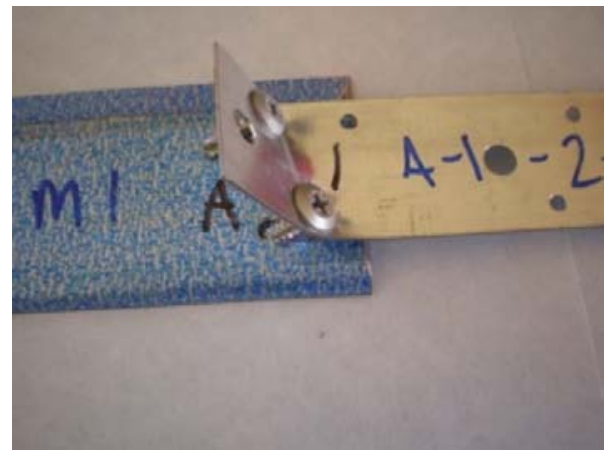

Tilting failure Specimen B-2-1-M1

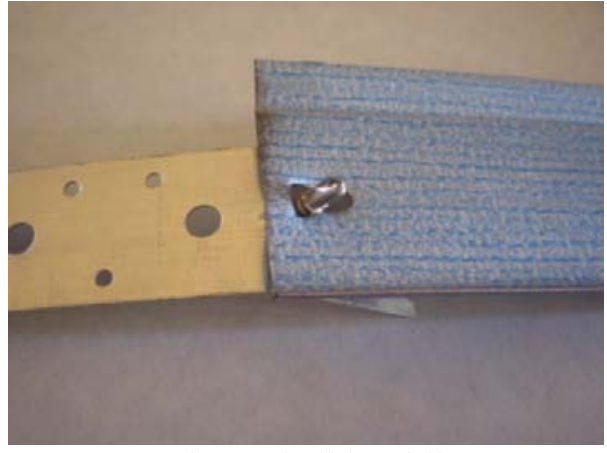

Bearing and Tilting failure Specimen B-1-1-M1

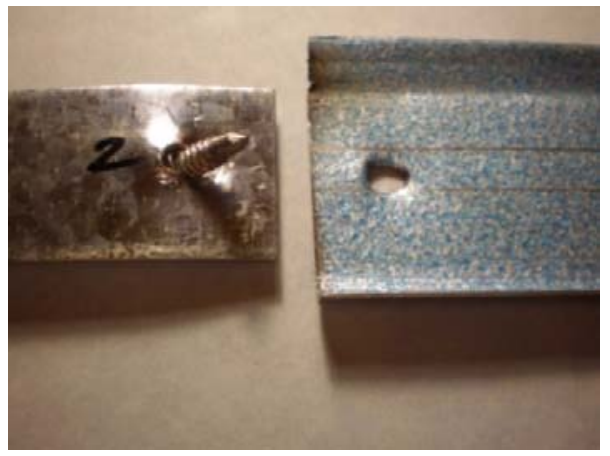

Pull-out failure

Specimen A-1-2-M1

Figure 17. Examples of Different Failure Modes

It should be noted that all of the specimens shown in Figure 17 ultimately failed by pull-out of the screws. An interesting combination of bearing, tilting, tear-out and pull-out was exhibited by the type 1 and 3 perforated straps connected to the type B $0.75 \mathrm{~mm}$ cold-formed steel with 2 screws. Only these 2 specimens exhibited this behavior in the monotonic tests. One of them is shown in Figure 18.

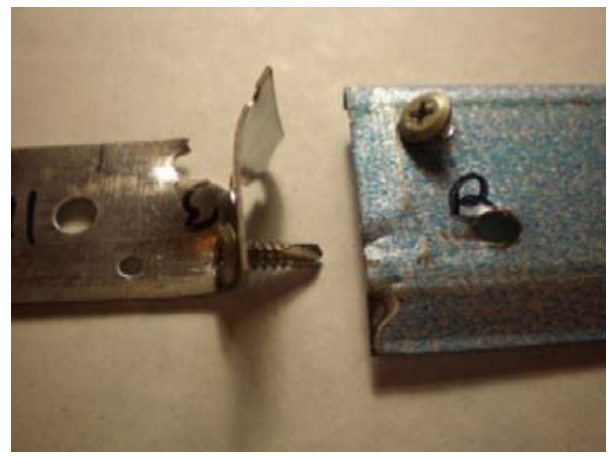

Figure 18. Bearing, Tilting, Tear-out and Pull-out Failure: Specimen B-3-2-M1

When sufficient screws are used, it is expected that the strap will fail either by net section failure at the connection or for the perforated straps at the weakest cross-section of the strap; or by excessive yielding, depending on the properties of the material. The four types of strap material types tested to have ultimate stress to yield stress ratios between 0.94 and 1.01 . These ratios reflect the closeness of values for the ultimate and yield stresses for these material and indicate that it is likely that net section failure will occur at loads which are near the yield point of a material. Some 
specimens may experience significant ductile extension before the ultimate failure occurs, while for others the net section failure could be quite sudden once the required load is applied to the connection. When selecting a strap bracing material it is desirable to use a material which not only is strong enough to resist the required design loads on a structure, but which also exhibits significant ductile behavior before the ultimate behavior of the bracing system. For most of the monotonic test specimens the ductility factor increased with increasing number of screws. This was because the failure mode of the specimens was only net section failure for the maximum number of screws tested. The other specimens failed by various combinations of pull-out, bearing, and tilting which occurred at lower loads than the ultimate load for the strap material, therefore not allowing them to fully develop the maximum ductility that the strap material is capable of. Examples of the net section failure that occurred at the connections of the strap bracing materials are shown in Figures 19.

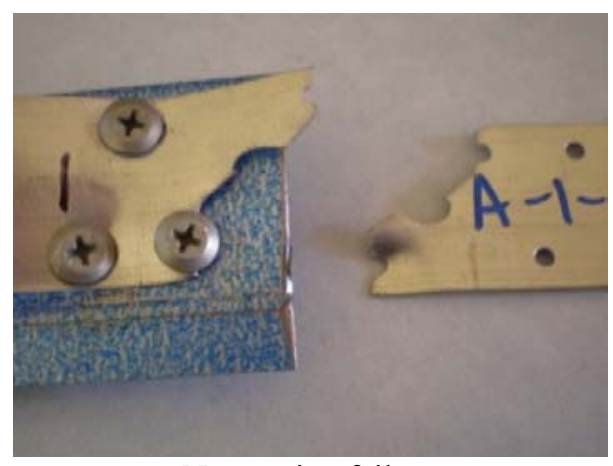

Net section failure Perforated strap Specimen A-1-3-M1

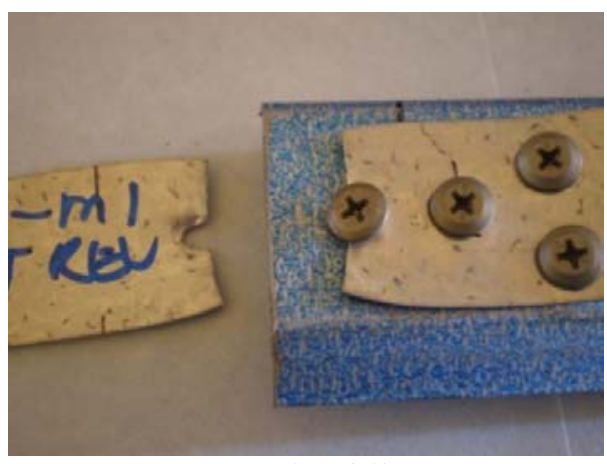

Net section failure Solid strap Specimen A-2-4-M1

Figure 19. Net Section Failure

When the perforated straps failed by net section failure, the failure always occurred at the same place in the perforation pattern of the straps as shown in Figure 20. This pattern in the strap has the lowest net area and therefore is the weakest part of the strap. The pattern repeats every $87 \mathrm{~mm}$ and as a result there was only one repetition between the grips of the testing rig.

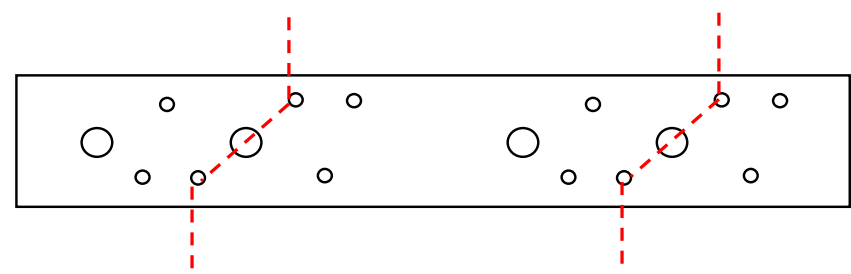

Figure 20. Perforated Strap Failure Location

An example of when the net section failure occurred away from the connection is shown in Figure 21. The weak area of the strap for this specimen was not near the connection, which resulted in the strap failure away from the connection. 


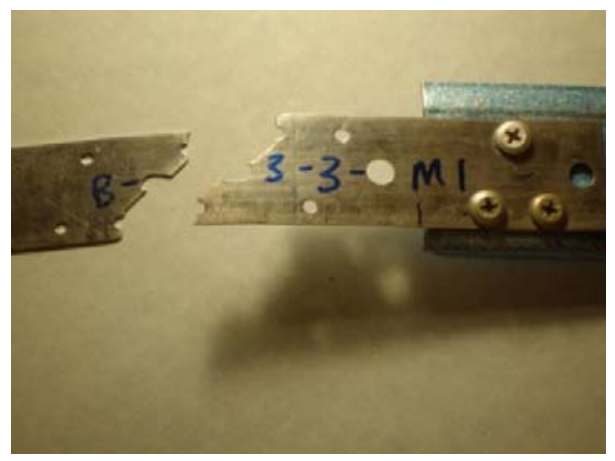

Figure 21. Net Section Failure away from the Connection: Specimen B-3-3-M1

For longer specimens of the perforated strap it would be expected that several of these weak areas at $87 \mathrm{~mm}$ would elongate when the strap was loaded beyond the yield strength of the material. Both types of perforated straps had ductility ratios which were higher than that of the type 2 strap (which has similar dimensions) when connected to the $0.55 \mathrm{~mm}$ cold-formed steel, but lower than the that of the type 2 strap when connected to the $0.75 \mathrm{~mm}$ cold-formed steel.

Another parameter which was used to gauge the performance of the connection is the yielding factor $R_{f}$. Because the yield stresses of the strap materials are similar to the ultimate stresses, for most of the specimens which failed by combinations of bearing, tilting and pull-out, failure occurred before the material had begun to yield at all and therefore the yielding factors of these specimens is less than one. Also, the elastic shear stiffness $\mathrm{K}_{\mathrm{e}}$ was calculated from the results of the strap bracing tests. Higher values of elastic shear stiffness indicate that a connection had a high stiffness and therefore more resistance to deformation during the elastic loading stage. In general, the solid strap materials exhibited higher elastic shear stiffness. The lower elastic shear stiffness of the perforated straps can be attributed to the yielding in the perforated straps at the narrower cross-sections of the strap material where there are significant perforations. These areas along the strap which have smaller cross sections yield at lower loads than the areas of the strap where there are fewer perforations. The perforations are intended to allow the strap material to deform with less resistance to load than if the strap was solid.

The thicker type B $0.75 \mathrm{~mm}$ cold-formed steel connections had a higher capacity than the thinner cold-formed steel connections for all strap types except the type thicker and wider type 4 strap. The greater thickness increases the connections' capacity in bearing, tilting and pull-out according to the design provisions of AS/NZS4600 and therefore this result was expected. The reduction in capacity for the type 4 strap with the thicker cold-formed steel can be attributed to the reduction in the number of screws required for net-section failure to become the governing failure mode. For the $0.55 \mathrm{~mm}$ cold-formed steel 6 screws are required while for the $0.75 \mathrm{~mm}$ cold-formed steel only 4 screws are required to prevent the failure modes which occur when insufficient screws are used (bearing, tilting, pull-out, tear-out and pull-over). The reduction is relatively small (3\%) and may also be due to specimen faults which occurred during assembly. 
Table 5. Cyclic Test Results on CFS Type A $(0.55 \mathrm{~mm})$

\begin{tabular}{|c|c|c|c|c|c|c|c|c|c|c|c|c|c|c|}
\hline & $\begin{array}{l}\text { Specimen } \\
\text { Name }\end{array}$ & $\begin{array}{l}\mathbf{P}_{\max } \\
(\mathrm{N})\end{array}$ & $\begin{array}{l}\mathbf{P}_{\mathbf{y}} \\
(\mathrm{N})\end{array}$ & $\begin{array}{c}\Delta_{\mathbf{y}} \\
(\mathrm{mm})\end{array}$ & $\begin{array}{l}\mathbf{P}_{\mathrm{u}} \\
(\mathrm{N})\end{array}$ & $\begin{array}{c}\boldsymbol{\Delta}_{\mathbf{u}} \\
(\mathrm{mm})\end{array}$ & $\begin{array}{c}\mathbf{A}_{\mathbf{g}} \\
\left(\mathrm{mm}^{2}\right)\end{array}$ & $\underset{\left(\mathrm{mm}^{2}\right)}{\mathbf{A}_{\mathbf{n}}}$ & $\begin{array}{l}\mathbf{A g}_{\mathbf{g}} \cdot \mathbf{F}_{\mathrm{y}} \\
(\mathrm{N})\end{array}$ & $\begin{array}{c}\mathbf{0 . 8 5} \\
\mathbf{A}_{\mathbf{n}} \cdot \mathbf{F}_{\mathbf{u}} \\
(\mathrm{N})\end{array}$ & $\mathbf{R}_{\mu}$ & $\mathbf{R}_{\mathbf{f}}$ & $\mathbf{K}_{\mathrm{e}}$ & Failure Mode \\
\hline \multirow{6}{*}{$\begin{array}{c}\text { Strap } \\
1\end{array}$} & $\mathrm{~A}-1-1-\mathrm{Cl}$ & 2856 & 1670 & 1.2 & 2285 & 5.5 & 22.9 & 16.2 & 5641 & 3200 & 4.58 & 0.51 & 1785 & $(\mathrm{~m}) \mathrm{B}+(\mathrm{m}) \mathrm{T}+\mathrm{PT}$ \\
\hline & \begin{tabular}{|l|}
$A-1-1-C 2$ \\
\end{tabular} & 3110 & 2119 & 1.65 & 2488 & 4.2 & 22.9 & 16.2 & 5641 & 3200 & 2.55 & 0.55 & 2145 & $(\mathrm{~s}) \mathrm{B}+(\mathrm{m}) \mathrm{T}+\mathrm{PT}$ \\
\hline & A-1-2-C1 & 4379 & 3048 & 1.22 & 4379 & 6.2 & 22.9 & 15.5 & 5641 & 3056 & 5.08 & 0.78 & 5229 & $(\mathrm{~m}) \mathrm{B}+(\mathrm{s}) \mathrm{T}+\mathrm{PT}$ \\
\hline & \begin{tabular}{|l|}
$A-1-2-C 2$ \\
\end{tabular} & 5359 & 3727 & 2.36 & 4287 & 7.1 & 22.9 & 15.5 & 5641 & 3056 & 3.01 & 0.95 & 6496 & $(\mathrm{~m}) \mathrm{B}+(\mathrm{m}) \mathrm{T}+\mathrm{PT}$ \\
\hline & \begin{tabular}{|l|}
$\mathrm{A}-1-3-\mathrm{C} 1$ \\
\end{tabular} & 6532 & 3732 & 0.9 & 5226 & 6.6 & 22.9 & 15.5 & 5641 & 3056 & 7.33 & 1.16 & 4768 & $\mathrm{~N} 5 \mathrm{~F}$ \\
\hline & A-1-3-C2 & 6068 & 5729 & 1.2 & 4854 & 3.8 & 22.9 & 15.5 & 5641 & 3056 & 3.17 & 1.08 & 4854 & NSF \\
\hline \multirow{6}{*}{$\begin{array}{c}\text { Strap } \\
3\end{array}$} & A-3-1-C1 & 2984 & 2063 & 1.8 & 2387 & 7.1 & 21.8 & 15.5 & 5916 & 3550 & 3.94 & 0.50 & 3226 & $(\mathrm{~m}) \mathrm{B}+(\mathrm{m}) \mathrm{T}+\mathrm{PT}$ \\
\hline & A-3-1-C2 & 2838 & 2705 & 1.97 & 2270 & 7.4 & 21.8 & 15.5 & 5916 & 3550 & 3.76 & 0.48 & 3662 & $(\mathrm{~m}) \mathrm{B}+(\mathrm{m}) \mathrm{T}+\mathrm{PT}$ \\
\hline & A-3-2-C1 & 5793 & 4571 & 1.5 & 4634 & 6.1 & 21.8 & 15.5 & 5916 & 3557 & 4.07 & 0.98 & 3049 & (m)B+(m)T+PT \\
\hline & \begin{tabular}{|l|}
$A-3-2-C 2$ \\
\end{tabular} & 6088 & 5282 & 2.4 & 4071 & 6.7 & 21.8 & 15.5 & 5916 & 3557 & 2.79 & 1.03 & 5940 & $(\mathrm{~s}) \mathrm{B}+(\mathrm{m}) \mathrm{T}+\mathrm{PT}$ \\
\hline & A-3-3-C1 & 6424 & 5522 & 2.2 & 5139 & 5.1 & 21.8 & 15.5 & 5916 & 3557 & 2.32 & 1.09 & 2495 & NSF \\
\hline & A-3-3-C2 & 6013 & 4203 & 1.1 & 4810 & 6.1 & 21.8 & 15.5 & 5916 & 3557 & 5.55 & 1.02 & 2559 & $(\mathrm{~m}) \mathrm{T}+\mathrm{NSF}$ \\
\hline \multirow{8}{*}{$\begin{array}{c}\text { Strap } \\
2\end{array}$} & A-2-1-C1 & 3273 & 2856 & 2.2 & 2618 & 7.3 & 24.5 & 20.5 & 7101 & 5106 & 3.32 & 0.46 & 1657 & (s) $\mathrm{B}+(\mathrm{s}) \mathrm{T}+\mathrm{PT}$ \\
\hline & A2-1-C2 & 3761 & 2340 & 0.9 & 3008 & 3.7 & 24.5 & 20.5 & 7101 & 5106 & 4.11 & 0.53 & 2180 & (s)B+(s) $\mathrm{T}+\mathrm{PT}$ \\
\hline & A-2-2-C1 & 4996 & 4804 & 1.9 & $39 \%$ & 6.6 & 24.5 & 20.5 & 7101 & 5106 & 3.47 & 0.70 & 6056 & $(\mathrm{~m}) \mathrm{B}+(\mathrm{s}) \mathrm{T}+\mathrm{PT}$ \\
\hline & A-2-2-C2 & 5712 & 3983 & 1.9 & 4570 & 5.8 & 24.5 & 20.5 & 7101 & 5106 & 3.05 & 0.80 & 4080 & $(\mathrm{~m}) \mathrm{B}+(\mathrm{s}) \mathrm{T}+\mathrm{PT}$ \\
\hline & A-2-3-C1 & 7528 & 6271 & 2.5 & 4570 & 11.5 & 24.5 & 20.5 & 7101 & 5106 & 4.60 & 1.06 & 6407 & $(\mathrm{~m}) \mathrm{B}+(\mathrm{s}) \mathrm{T}+\mathrm{PT}$ \\
\hline & A-2-3-C2 & 7435 & 6936 & 1.9 & 5948 & 5.4 & 24.5 & 20.5 & 7101 & 5106 & 2.84 & 1.05 & 8038 & $(\mathrm{~m}) \mathrm{B}+(\$) \mathrm{T}+\mathrm{PT}$ \\
\hline & A-2-4-C1 & 7922 & 7284 & 3.2 & 6338 & 9.4 & 24.5 & 20.5 & 7101 & 8584 & 2.94 & 1.12 & 7042 & NSF \\
\hline & A-2-4-C2 & 7770 & 4251 & 0.8 & 6216 & 8.1 & 24.5 & 20.5 & 7101 & 8584 & 10.13 & 1.09 & 6907 & NSF \\
\hline \multirow{6}{*}{$\begin{array}{c}\text { Strap } \\
4\end{array}$} & A-4-4-C1 & 10713 & 10704 & 3.9 & 8570 & 5.7 & 38.5 & 33.9 & 11626 & 8584 & 1.46 & 0.92 & 6593 & (s)B+(s)T+PT \\
\hline & A-4-4C2 & 11152 & 10652 & 3.2 & 8922 & 5.9 & 38.5 & 33.9 & 11626 & 8584 & 1.84 & 0.96 & 7435 & $(\mathrm{~s}) \mathrm{B}+(\mathrm{m}) \mathrm{T}+\mathrm{PT}$ \\
\hline & A-4-5-C1 & 11614 & 10388 & 2 & 9291 & 10.3 & 38.5 & 33.9 & 11626 & 8584 & 5.15 & 1.00 & 7834 & (s)B+PT \\
\hline & A-4-5-C2 & 12428 & 10533 & 2.5 & 9943 & 20.6 & 38.5 & 33.9 & 11626 & 8584 & 8.24 & 1.07 & 8527 & (s)B+PT \\
\hline & A-4-6-C1 & 13573 & 11358 & 1.6 & 10860 & 9 & 38.5 & 33.9 & 11626 & 8584 & 5.63 & 1.17 & 10858 & NSF \\
\hline & A-4-6-C2 & 13681 & 9583 & 1.6 & 10945 & 12 & 38.5 & 33.9 & 11626 & 8584 & 7.50 & 1.18 & 10945 & $(\mathrm{~m}) \mathrm{T}+\mathrm{NSF}$ \\
\hline
\end{tabular}

Table 6. Cyclic Test Results on CFS type B $(0.75 \mathrm{~mm})$

\begin{tabular}{|c|c|c|c|c|c|c|c|c|c|c|c|c|c|c|}
\hline & $\begin{array}{c}\text { Specimen } \\
\text { Name }\end{array}$ & $\begin{array}{l}P_{\max } \\
(\mathrm{N})\end{array}$ & $\begin{array}{c}\mathbf{P y}_{\mathbf{y}} \\
(\mathrm{N})\end{array}$ & $\begin{array}{c}\boldsymbol{\Delta}_{\mathbf{y}} \\
(\mathrm{mm})\end{array}$ & $\begin{array}{c}\mathbf{P u}_{\mathbf{u}} \\
(\mathrm{N})\end{array}$ & $\begin{array}{c}\boldsymbol{\Delta}_{\mathbf{u}} \\
(\mathrm{mm})\end{array}$ & $\begin{array}{c}\mathbf{A}_{\mathbf{g}} \\
\left(\mathrm{mm}^{2}\right)\end{array}$ & $\begin{array}{c}\mathbf{A}_{\mathbf{n}} \\
\left(\mathrm{mm}^{2}\right)\end{array}$ & $\begin{array}{c}\mathbf{A}_{\mathbf{g}} \cdot \mathbf{F}_{\mathbf{y}} \\
(\mathrm{N})\end{array}$ & $\begin{array}{c}\mathbf{0 . 8 5} \\
\mathrm{A}_{n} \cdot \mathrm{F}_{\mathrm{u}} \\
(\mathrm{N})\end{array}$ & $\mathbf{R}_{\mu}$ & $\mathbf{R}_{\mathrm{f}}$ & $\mathbf{K}_{\mathrm{e}}$ & Failure Mode \\
\hline \multirow{6}{*}{$\begin{array}{c}\text { Strap } \\
1\end{array}$} & B-l-l-Cl & 3601 & 2390 & 0.7 & 2881 & 6.7 & 22.9 & 16.2 & 5641 & 3200 & 9.57 & 0.64 & 3893 & (m)B+PR \\
\hline & B-1-1-C2 & 3729 & 1626 & 0.7 & 2984 & 7 & 22.9 & 16.2 & 5641 & 3200 & 10.00 & 0.66 & 3551 & (m)B+PR \\
\hline & B-1-2-C1 & 6399 & 5324 & 2 & 5119 & 4.8 & 22.9 & 15.5 & 5641 & 3056 & 2.40 & 1.13 & 4654 & (s)T+PT+TR \\
\hline & B-1-2-C 2 & 6362 & 5427 & 1.5 & 5089 & 6.3 & 22.9 & 15.5 & 5641 & 3056 & 4.20 & 1.13 & 7485 & $(\mathrm{~s}) \mathrm{B}+(\mathrm{m}) \mathrm{T}+\mathrm{PT}$ \\
\hline & B-1-3-C1 & 6215 & 5076 & 1.6 & 4972 & 4.8 & 22.9 & 15.5 & 5641 & 3056 & 3.00 & 1.10 & 5524 & NSF \\
\hline & B-1-3-C2 & 6524 & 4390 & 1.2 & 5219 & 5.3 & 22.9 & 15.5 & 5641 & 3056 & 4.42 & 1.16 & 4745 & NSF \\
\hline \multirow{6}{*}{$\begin{array}{c}\text { Strap } \\
\mathbf{3}\end{array}$} & B-3-1-C1 & 3705 & 2980 & 2.8 & 2964 & 7.1 & 21.8 & 15.5 & 5916 & 3550 & 2.54 & 0.63 & 1560 & $(\mathrm{~s}) \mathrm{B}+(\mathrm{m}) \mathrm{T}+\mathrm{PT}$ \\
\hline & B-3-1-C2 & 3765 & 3277 & 2.6 & 3012 & 7.2 & 21.8 & 15.5 & 5916 & 3550 & 2.77 & 0.64 & 2215 & $(\mathrm{~s}) \mathrm{B}+(\mathrm{s}) \mathrm{T}+\mathrm{PT}$ \\
\hline & B-3-2-C1 & 6581 & 6133 & 2.2 & 5265 & 6.9 & 21.8 & 15.5 & 5916 & 3557 & 3.14 & 1.11 & 5850 & $(\mathrm{~m}) \mathrm{B}+(\mathrm{m}) \mathrm{T}+\mathrm{PT}$ \\
\hline & B-3-2-C2 & 6436 & 4503 & 1.6 & 5149 & 6.2 & 21.8 & 15.5 & 5916 & 3557 & 3.88 & 1.09 & 4291 & $(\mathrm{~m}) \mathrm{B}+(\mathrm{m}) \mathrm{T}+\mathrm{NSF}$ \\
\hline & B-3-3-C1 & 6732 & 6505 & 2.5 & 5385 & 4.4 & 21.8 & 15.5 & 5916 & 3557 & 1.76 & 1.14 & 4371 & NSF \\
\hline & B-3-3-C2 & 6141 & 5321 & 1.2 & 4913 & 5.4 & 21.8 & 15.5 & 5916 & 3557 & 4.50 & 1.04 & 7018 & NSF \\
\hline \multirow{6}{*}{$\begin{array}{c}\text { Strap } \\
2\end{array}$} & B-2-1-C1 & 4082 & 2802 & 2.1 & 3265 & 6.7 & 24.5 & 20.5 & 7101 & 5106 & 3.19 & 0.57 & 3474 & $(\mathrm{~m}) \mathrm{T}+\mathrm{PR}$ \\
\hline & B-2-1-C2 & 3877 & 2725 & 1.2 & 3101 & 7.4 & 24.5 & 20.5 & 7101 & 5106 & 6.17 & 0.55 & 4431 & $(\mathrm{~S}) \mathrm{T}+\mathrm{PT}$ \\
\hline & B-2-2-C1 & 6618 & 6044 & 2.4 & 5294 & 8.5 & 24.5 & 20.5 & 7101 & 5106 & 3.54 & 0.93 & 6618 & $(\mathrm{~m}) \mathrm{B}+(\mathrm{s}) \mathrm{T}+\mathrm{PT}$ \\
\hline & B-2-2-C2 & 6270 & 5701 & 1.8 & 5016 & 7.1 & 24.5 & 20.5 & 7101 & 5106 & 3.94 & 0.88 & 7600 & $(\mathrm{~s}) \mathrm{T}+\mathrm{PT}$ \\
\hline & B-2-3-C1 & 7591 & 6092 & 1.2 & 6073 & 9.7 & 24.5 & 20.5 & 7101 & 5106 & 8.08 & 1.07 & 9201 & (m)T+NSF \\
\hline & B-2-3-C2 & 8301 & 7045 & 2.2 & 6641 & 13.6 & 24.5 & 20.5 & 7101 & 5106 & 6.18 & 1.17 & 10711 & $(\mathrm{~m}) \mathrm{T}+\mathrm{NSF}$ \\
\hline \multirow{6}{*}{$\begin{array}{c}\text { Strap } \\
\mathbf{4}\end{array}$} & B-4-2-C1 & 6730 & 3018 & 1.1 & 5384 & 6 & 38.5 & 33.9 & 11626 & 8584 & 5.45 & 0.58 & 2926 & $(\mathrm{~m}) \mathrm{T}+\mathrm{PT}$ \\
\hline & B-4-2-C2 & 7036 & 4286 & 0.86 & 5629 & 6.85 & 38.5 & 33.9 & 11626 & 8584 & 7.97 & 0.61 & 4021 & $(\mathrm{~m}) \mathrm{T}+\mathrm{PT}$ \\
\hline & B-4-3-C1 & 9924 & 8804 & 2.4 & 7939 & 6.7 & 38.5 & 33.9 & 11626 & 8584 & 2.79 & 0.85 & 7939 & $(\mathrm{~m}) \mathrm{B}+(\mathrm{m}) \mathrm{T}+\mathrm{PT}$ \\
\hline & B-4-3-C2 & 9874 & 9185 & 2.3 & 7900 & 6.3 & 38.5 & 33.9 & 11626 & 8584 & 2.74 & 0.85 & 11285 & $(\mathrm{~m}) \mathrm{B}+(\mathrm{m}) \mathrm{T}+\mathrm{PT}$ \\
\hline & B-4-4-C1 & 12956 & 11548 & 4.3 & 10364 & 15.2 & 38.5 & 33.9 & 11626 & 8584 & 3.53 & 1.11 & 6478 & (m)T+NSF \\
\hline & B-4-4-C2 & 13278 & 11208 & 2 & 10622 & 12.5 & 38.5 & 33.9 & 11626 & 8584 & 6.25 & 1.14 & 8852 & (m)T+NSF \\
\hline
\end{tabular}


The cyclic test specimens exhibited similar failure modes to their corresponding monotonically tested specimens. As for the monotonically tested specimens, all the specimens with fewer screws (except Specimen A-3-2-C2) failed by combinations of bearing, tilting and eventual pull-out. There was one additional failure mode that occurred only in one of the type 2 solid strap and type B, $0.75 \mathrm{~mm}$ cold-formed steel specimens, which was pull-over (see Figure 22). The strap curled up at the end and deformed around the hole before eventually pulling clear of the screw head. Pull over might be a result of the screw not having been fastened accurately, or there may some initial tearing at the hole in the strap due to imperfections in the strap caused during the assembly of the connection.

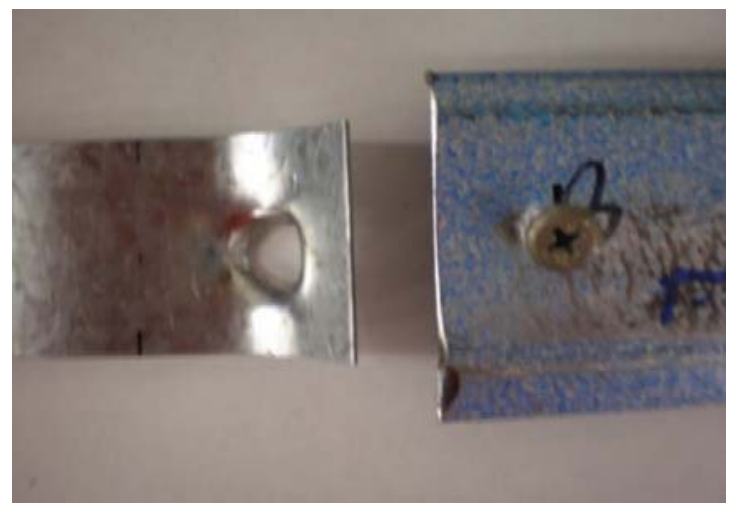

Figure 22. Pull-over Failure: Specimen B-2-1-C1

It should be noted that when considering the hysteresis curves for each specimen whilst the specimens were only subjected to positive extension, after plastic deformation began to take place in the specimen, residual strain occurred and so there was some small compression load on the specimen. When the specimen was returned to zero extension, the specimen had lengthened and therefore the stiffness of the specimens caused them to take the small compression loads. This behavior is shown in Figure 23.

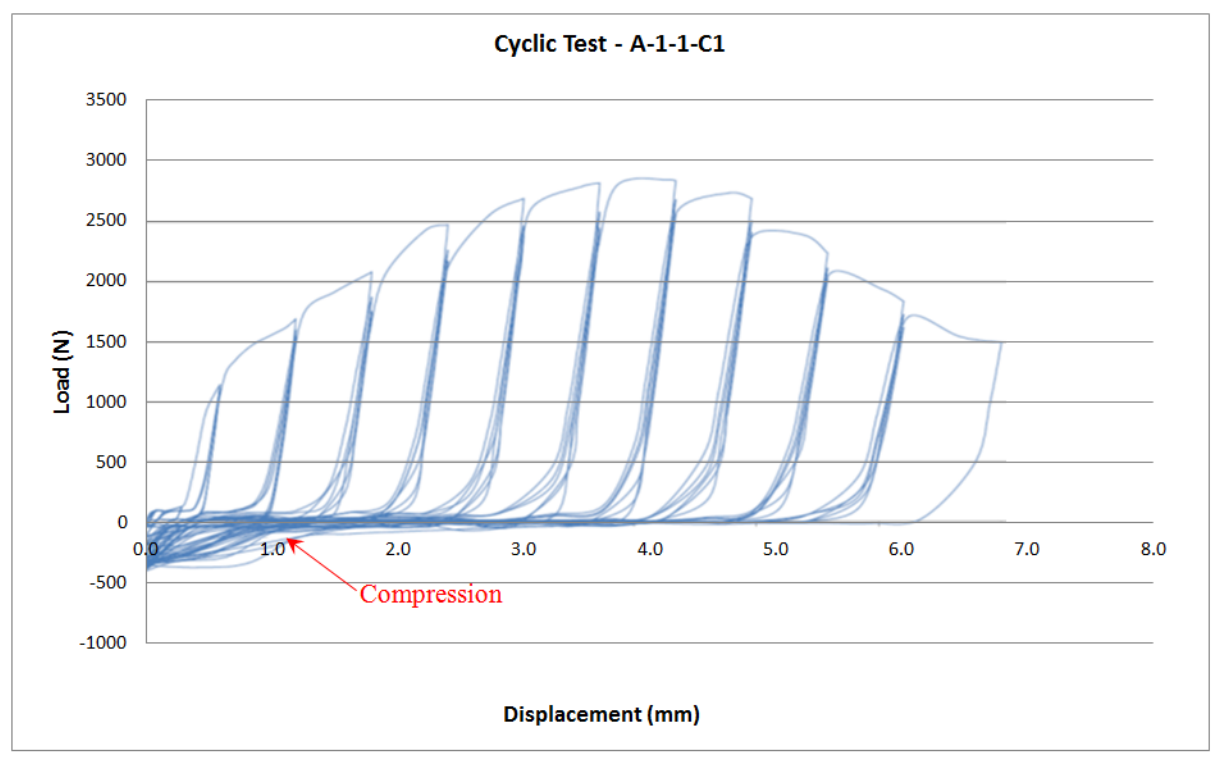

Figure 23. Compression Load in Cyclic Tests 
The envelope of cyclic hysteresis curves showed similar relationships to the monotonic load-extension curves. The hysteresis curve presented in Figure 24 shows that the solid strap exhibited significant displacement before the ultimate load was reached.

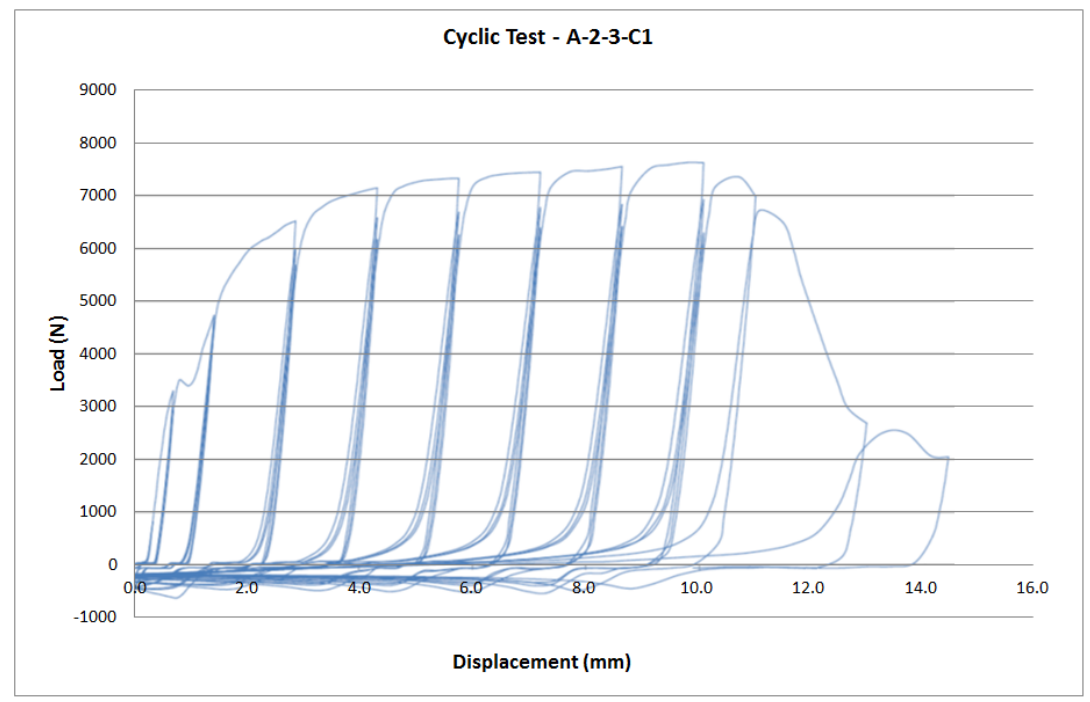

Figure 24. Hysteresis Curve for Solid Strap

In contrast Figure 25 shows that the load perforated strap dropped sraight after yield as pull-out occurred. This behavious was also shown in Figure 15 for a monotonic test on a perforated strap which failed by pull-out.

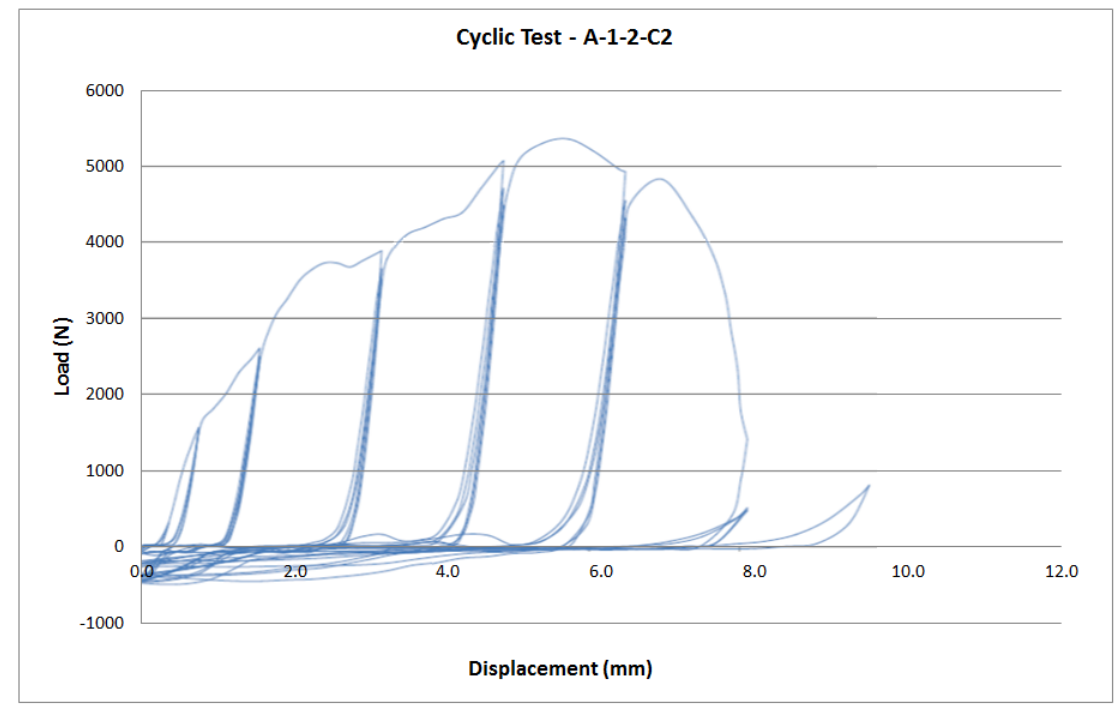

Figure 25. Hysteresis Curve for Perforated Strap

Table 7 presents a comparison between the monotonic and cyclic test results for the connections. 
Table 7. Comparison of Monotonic and Cyclic Ultimate Loads (Pu)

\begin{tabular}{|c|c|c|c|c|c|}
\hline & & $\begin{array}{c}\text { Number } \\
\text { of } \\
\text { Screws }\end{array}$ & $\begin{array}{c}\mathbf{P}_{\mathrm{u}} \\
\text { Monotonic Tests } \\
\text { (N) }\end{array}$ & $\begin{array}{c}P_{u} \\
\text { Average of } \\
\text { Cyclic Tests } \\
\text { (N) }\end{array}$ & $\begin{array}{l}\text { \% Increase } \\
\text { in Pu due } \\
\text { to Cyclic } \\
\text { Hardening }\end{array}$ \\
\hline \multirow{13}{*}{$\begin{array}{c}\text { CFS } \\
\text { Type A } \\
0.55 \mathrm{~mm}\end{array}$} & \multirow{3}{*}{ Strap 1} & 1 & 1980 & 2387 & 0.21 \\
\hline & & 2 & 3820 & 4333 & 0.02 \\
\hline & & 3 & 4860 & 5040 & 0.04 \\
\hline & \multirow{3}{*}{ Strap 3} & 1 & 2130 & 2329 & 0.09 \\
\hline & & 2 & 3820 & 4353 & 0.25 \\
\hline & & 3 & 5260 & 4975 & -0.05 \\
\hline & \multirow{4}{*}{ Strap 2} & 1 & 2260 & 2813 & 0.25 \\
\hline & & 2 & 4120 & 4283 & 0.04 \\
\hline & & 3 & 5600 & 5259 & 0.07 \\
\hline & & 4 & 6260 & 6277 & 0.00 \\
\hline & \multirow{3}{*}{ Strap 4} & 4 & 8440 & 8746 & 0.04 \\
\hline & & 5 & 9260 & 9617 & 0.04 \\
\hline & & 6 & 10430 & 10903 & 0.05 \\
\hline \multirow{12}{*}{$\begin{array}{c}\text { CFS } \\
\text { Type B } \\
0.75 \mathrm{~mm}\end{array}$} & \multirow{3}{*}{ Strap 1} & 1 & 3040 & 2933 & -0.04 \\
\hline & & 2 & 5000 & 5104 & 0.02 \\
\hline & & 3 & 5410 & 5096 & -0.06 \\
\hline & \multirow{3}{*}{ Strap 3} & 1 & 2680 & 2988 & 0.11 \\
\hline & & 2 & 5270 & 5207 & -0.01 \\
\hline & & 3 & 5440 & 5149 & -0.05 \\
\hline & \multirow{3}{*}{ Strap 2} & 1 & 3130 & 3183 & 0.02 \\
\hline & & 2 & 5020 & 5155 & 0.03 \\
\hline & & 3 & 6440 & 6357 & -0.01 \\
\hline & \multirow{3}{*}{ Strap 4} & 2 & 5140 & 5507 & 0.07 \\
\hline & & 3 & 7380 & 7920 & 0.07 \\
\hline & & 4 & 10140 & 10493 & 0.04 \\
\hline
\end{tabular}

A general trend which was exhibited by most of the strap bracing connections was that the maximum cyclic load for each connection was greater than the maximum monotonic load for the same connection type. This indicates that the strap bracing material underwent cyclic hardening as a result of the repeated loading which allowed the specimens to resist a slightly higher maximum load. There were a number of exceptions that occurred in the type 1 and 3 perforated strap connections, however this could be attributed to the variable nature of the perforated strap specimens, where there may have been more occurrences of the weaker perforation patterns in some specimens compared to the others. The cyclic hardening that did occur in specimens resulted in maximum load increases of less than $10 \%$ more than the maximum monotonic loads, which indicates that the hardening effect was small. The instances where the increase in load was significantly higher at around $20 \%$ were for connections with 1 or 2 screws in perforated strap material. The reason for this increase may be that there was some error involved in assembling the specimens, or because of the variability of the section of the perforated pattern which was included in each specimen. 
In general the elastic shear stiffness was greater for the monotonic specimens for all strap types with the thicker $0.75 \mathrm{~mm}$ cold-formed steel, and for the type 1 and 3 perforated straps with the $0.55 \mathrm{~mm}$ cold-formed steel. The initial cycles in the cyclic tests appear to have reduced the stiffness of the specimens. The yielding factor $R_{f}$ was similar for the monotonic and cyclic specimens; the specimens which experienced net section failure had exhibited some yielding leading up to failure and therefore had yielding factors which were above 1, and the specimens which failed in other modes generally had yielding factors which were less than 1 .

Generally, the $0.75 \mathrm{~mm}$ cold-formed steel increased the capacity of the strap bracing connections by $3-11 \%$ more than the $0.55 \mathrm{~mm}$ cold-formed steel due to the increased anchorage of the connection. The maximum screw connections in the perforated straps had higher ductility ratios when connected to the $0.55 \mathrm{~mm}$ cold-formed steel than the type 2 strap which had the same gross cross-sectional area (ignoring perforations), while in the $0.75 \mathrm{~mm}$ cold-formed steel the opposite was true. However, for both the $0.75 \mathrm{~mm}$ and the $0.55 \mathrm{~mm}$ cold-formed steel connections the actual extension of the straps at ultimate strength was significantly higher for the type 2 solid strap material than both of the perforated strap materials.

Of the two perforated strap materials with the maximum number of screws: the type 3 strap had between $1 \%$ and $8 \%$ more capacity than the type 1 strap in the monotonic tests, and similar results for the cyclic tests. The type 3 strap also exhibited higher extensions at the ultimate load. In comparison to the perforated straps, the solid strap type 2 (of similar dimensions to the perforated straps) exhibited higher capacities which were approximately 18\% more than those of the type 3 perforated straps in both thicknesses of cold formed steel. The type 2 strap also demonstrated greater extensions than the perforated straps at ultimate load.

The type 4 solid strap fastened with the maximum numbers of screws had ultimate capacities which were $67 \%$ and $57 \%$ higher than the ultimate capacities of the type 2 solid strap when connected to the $0.55 \mathrm{~mm}$ and $0.75 \mathrm{~mm}$ cold-formed steels, respectively. These increases in capacity are due to the significantly large cross-section of the type 4 strap. The type 4 straps demonstrated significantly higher extension at ultimate load in the $0.55 \mathrm{~mm}$ cold-formed steel than of the type 2 solid strap, and similar extension in the $0.75 \mathrm{~mm}$ cold-formed steel.

The slightly lower capacity and extension of the type 4 strap in the $0.75 \mathrm{~mm}$ cold-formed steel compared to the $0.55 \mathrm{~mm}$ cold-formed steel could possibly be increased by increasing the number of screws in the connection. However, net section would still be the limiting failure mode of the connection, and it is expected that the increases that could be obtained with extra screws would not be large, particularly with regards to the extension. Therefore the advantage of using fewer screws was deemed more efficient than the small increases that are to be gained in capacity. Finally the screw requirements and capacities of the connections are summarized below:

- The type 1 perforated strap bracing requires 3 screws in order to obtain the maximum capacity in the strap bracing system. When connected to the $0.55 \mathrm{~mm}$ thick cold-formed steel (CFS) this connection has a capacity of $4.9 \mathrm{kN}$, and when connected to $0.75 \mathrm{~mm}$ CFS the capacity is $11 \%$ higher at $5.4 \mathrm{kN}$.

- The type 3 perforated strap bracing requires 3 screws and has a capacity of $5.3 \mathrm{kN}$ when connected to $0.55 \mathrm{~mm}$ CFS, and a capacity which is $3 \%$ higher when connected to $0.75 \mathrm{~mm}$ CFS at $5.4 \mathrm{kN}$.

- The type 2 solid strap bracing requires 4 screws in the pattern specified in Section 4.2. When connected to the $0.55 \mathrm{~mm}$ CFS these connections have a capacity of $6.3 \mathrm{kN}$, and a capacity which is $3 \%$ higher when connected to $0.75 \mathrm{~mm}$ CFS. 
- The type 4 solid strap bracing requires 6 screws when it is connected to $0.55 \mathrm{~mm}$ CFS, and 4 screws when it is connected to $0.75 \mathrm{~mm}$ CFS. The 4 -screw connection to the $0.75 \mathrm{~mm}$ CFS has $3 \%$ less capacity than the 6 -screw connection to the $0.55 \mathrm{~mm}$ CFS.

On the following, the capacities for the connections calculated based on the design codes (AS/NZS 4600 [9], AISI-S100 [23] and Eurocode3 [24]) will be compared with the capacities found from the experimental results.

Table 8. Strap Bracing Experimental Capacities Compared to

Design Capacities from AS/NZS4600 (N)

\begin{tabular}{|c|c|c|c|c|c|c|c|c|c|c|c|c|c|c|c|}
\hline & & \multirow{2}{*}{$\begin{array}{c}\text { Screws } \\
\text { number }\end{array}$} & \multirow{2}{*}{$\begin{array}{c}\text { Pu } \\
\text { Monotonic } \\
\text { Tests }\end{array}$} & \multicolumn{2}{|c|}{$\begin{array}{c}\text { Net-Section } \\
\text { Tension } \\
\text { Failure }\end{array}$} & \multicolumn{2}{|c|}{$\begin{array}{l}\text { Bearing } \\
\text { Failure }\end{array}$} & \multicolumn{2}{|c|}{$\begin{array}{l}\text { Tear-out - } \\
\text { strap }\end{array}$} & \multicolumn{2}{|c|}{ Pull-out } & \multicolumn{2}{|c|}{ Pull-over } & \multirow{2}{*}{$\begin{array}{c}\text { Limiting } \\
\text { Factored } \\
\text { Design } \\
\text { Capacity }\end{array}$} & \multirow{2}{*}{$\begin{array}{c}\text { Related } \\
\text { Failure } \\
\text { Mode }\end{array}$} \\
\hline & & & & $\mathbf{N}_{\mathrm{t}}$ & $\phi N_{t}$ & $V_{b}$ & $\phi V_{b}$ & $\mathbf{V}_{\mathrm{fv}}$ & $\phi V_{f v}$ & $\mathbf{N}_{\text {ou }}$ & $\phi \mathrm{N}_{\text {ou }}$ & $\mathbf{N}_{\text {ov }}$ & $\phi N_{o v}$ & & \\
\hline \multirow{13}{*}{$\begin{array}{c}\text { CFS } \\
\text { Type A } \\
0.55 \mathrm{~mm}\end{array}$} & \multirow{3}{*}{$\begin{array}{c}\text { Strap } \\
1\end{array}$} & 1 & 1980 & 1536 & 999 & \begin{tabular}{|l|}
2317 \\
\end{tabular} & 1150 & 2714 & 1629 & 1385 & 693 & 2443 & 1221 & OS & PT \\
\hline & & 2 & 3820 & 3764 & 2447 & 4633 & & 5429 & & 2770 & & 4886 & & & PT \\
\hline & & 3 & 4860 & 3596 & 2337 & \begin{tabular}{|l|}
6950 \\
\end{tabular} & 3475 & 8143 & 4886 & 4155 & \begin{tabular}{|l|}
2078 \\
\end{tabular} & 7329 & 3664 & 2078 & $\mathrm{PT}$ \\
\hline & \multirow{3}{*}{$\begin{array}{c}\text { Strap } \\
3\end{array}$} & 1 & 2130 & 1699 & 1104 & \begin{tabular}{|l|}
2317 \\
\end{tabular} & 1158 & 2997 & 1798 & 1385 & 693 & 2697 & 1349 & 693 & PT \\
\hline & & 2 & 3820 & 4176 & 2715 & 4633 & 2317 & 5994 & 3596 & 2770 & 1385 & 5395 & 2697 & 1385 & PT \\
\hline & & 3 & 5260 & 4185 & 2720 & \begin{tabular}{|l|}
6950 \\
\end{tabular} & 3475 & 8991 & 5395 & 4155 & \begin{tabular}{|l|}
2078 \\
\end{tabular} & 8092 & 4046 & 2078 & $\mathrm{PT}$ \\
\hline & \multirow{4}{*}{$\begin{array}{c}\text { Strap } \\
2\end{array}$} & 1 & 2260 & 2443 & 1588 & 2317 & 1158 & 3648 & 2189 & 1385 & 693 & 3283 & 1642 & 693 & PT \\
\hline & & 2 & 4120 & 6007 & 3904 & 4633 & 2317 & 7296 & 4377 & 2770 & 1385 & 56 & 3283 & 1 & PT \\
\hline & & 3 & 5600 & 6007 & 3904 & 6950 & 3475 & 10944 & 6566 & 4155 & 2078 & 9849 & 4925 & 2078 & PT \\
\hline & & 4 & 6260 & 6007 & 3904 & 9267 & 4633 & 14591 & 8755 & 5540 & 2770 & 13132 & 6566 & 2770 & PT \\
\hline & \multirow{3}{*}{$\begin{array}{c}\text { Strap } \\
4\end{array}$} & 4 & & 6007 & 3904 & 9267 & 4633 & 17165 & 10299 & 5540 & 2770 & 15448 & 7724 & & PT \\
\hline & & 5 & 9260 & 10099 & 6564 & \begin{tabular}{|l|}
11584 \\
\end{tabular} & 5792 & 21456 & 12874 & 6926 & \begin{tabular}{|l|}
3463 \\
\end{tabular} & 19310 & 9655 & 34 & PT \\
\hline & & 6 & 10430 & 10099 & 6564 & 13900 & 6950 & 25747 & 15448 & 8311 & 4155 & 23172 & 11586 & 4155 & PT \\
\hline \multirow{12}{*}{$\begin{array}{l}\text { CFS } \\
\text { Type B } \\
\text { 0.75mm }\end{array}$} & \multirow{3}{*}{$\begin{array}{c}\text { Strap } \\
1\end{array}$} & 1 & 3040 & 1536 & 999 & 2332 & 1166 & 2714 & 1629 & 1802 & 901 & 2443 & 1221 & 901 & PT \\
\hline & & 2 & 5000 & 3764 & 2447 & 4664 & 2332 & 5429 & 3257 & 3605 & 1802 & 4886 & 2443 & 1802 & PT \\
\hline & & 3 & 5410 & 3596 & 2337 & 6996 & 3498 & 8143 & 4886 & 5407 & 2704 & 7329 & 3664 & 2337 & NSF \\
\hline & \multirow{3}{*}{$\begin{array}{c}\text { Strap } \\
3\end{array}$} & 1 & 2680 & 1699 & 1104 & 2543 & 1272 & 2997 & 1798 & 1802 & & 2697 & 1349 & & PT \\
\hline & & 2 & 5270 & 4176 & 2715 & 5086 & 2543 & 5994 & 3596 & 3605 & 1802 & 5395 & 2697 & 1802 & PT \\
\hline & & 3 & 5440 & 4185 & 2720 & 7630 & 3815 & 8991 & 5395 & 5407 & 2704 & 8092 & 4046 & 2704 & PT \\
\hline & \multirow{3}{*}{$\begin{array}{c}\text { Strap } \\
2\end{array}$} & 1 & 3130 & 2443 & 1588 & 3152 & 1576 & 3648 & 2189 & 1802 & 901 & 3283 & 1642 & 901 & PT \\
\hline & & 2 & 5020 & 6007 & 3904 & 6303 & 3152 & 7296 & 4377 & 3605 & 1802 & 6566 & 3283 & 1802 & PT \\
\hline & & 3 & 6440 & 6007 & 3904 & 9455 & 4728 & 10944 & 6566 & 5407 & 2704 & 9849 & 4925 & 2704 & PT \\
\hline & \multirow{3}{*}{$\begin{array}{c}\text { Strap } \\
4\end{array}$} & 2 & 5140 & 3022 & 1964 & \begin{tabular}{|l|}
7041 \\
\end{tabular} & 3520 & 8582 & 5149 & 3605 & 1802 & 7724 & 3862 & 1802 & PT \\
\hline & & 3 & 7380 & 10099 & 6564 & 10561 & 5280 & 12874 & 7724 & 5407 & 2704 & 11586 & 5793 & 2704 & PT \\
\hline & & 4 & 10140 & 10099 & 6564 & 14081 & 7041 & 17165 & 10299 & 7209 & 3605 & 15448 & 7724 & 3605 & PT \\
\hline
\end{tabular}

Table 9. Strap Bracing Experimental Capacities Compared to

Design Capacities from the AISI-S100 [23] (N)

\begin{tabular}{|c|c|c|c|c|c|c|c|c|c|c|c|c|c|}
\hline & \multirow{2}{*}{$\begin{array}{l}\text { Screws } \\
\text { number }\end{array}$} & \multirow{2}{*}{$\begin{array}{c}\text { Pu } \\
\text { Monotonic } \\
\text { Tests }\end{array}$} & \multicolumn{2}{|c|}{$\begin{array}{l}\text { Bearing } \\
\text { Failure }\end{array}$} & \multicolumn{2}{|c|}{ Tear-out - strap } & \multicolumn{2}{|c|}{ Pull-out } & \multicolumn{2}{|c|}{ Pull-over } & \multirow{2}{*}{$\begin{array}{c}\text { Limiting } \\
\text { Factored } \\
\text { Design } \\
\text { Capacity }\end{array}$} & \multirow{2}{*}{$\begin{array}{l}\text { Related } \\
\text { Failure } \\
\text { Mode }\end{array}$} \\
\hline & & & & $V_{b}$ & $\phi V_{b}$ & $\mathbf{V}_{\mathrm{fv}}$ & $\phi V_{f v}$ & $\mathbf{N}_{\text {ou }}$ & $\phi \mathbf{N}_{\text {ou }}$ & $\mathbf{N}_{\text {ov }}$ & $\phi \mathbf{N}_{\mathrm{ov}}$ & & \\
\hline \multirow{13}{*}{$\begin{array}{c}\text { CFS } \\
\text { Type A } \\
0.55 \mathrm{~mm}\end{array}$} & \multirow{3}{*}{$\begin{array}{c}\text { Strap } \\
1\end{array}$} & 1 & 1980 & 2317 & 1158 & 2714 & 1357 & 1385 & 693 & 2443 & 1221 & 693 & PT \\
\hline & & 2 & 3820 & 4633 & 2317 & 5429 & 2714 & 2770 & 1385 & 4886 & 2443 & 1385 & PT \\
\hline & & 3 & 4860 & 6950 & 3475 & 8143 & 4072 & 4155 & 2078 & 7329 & 3664 & 2078 & PT \\
\hline & \multirow{3}{*}{$\begin{array}{c}\text { Strap } \\
\mathbf{3}\end{array}$} & 1 & 2130 & 2317 & 1158 & 2997 & 1499 & 1385 & 693 & 2697 & 1349 & 693 & PT \\
\hline & & 2 & 3820 & 44633 & 2317 & 5994 & 2997 & 2770 & 1385 & 5395 & 2697 & 1385 & PT \\
\hline & & 3 & 5260 & 6950 & 3475 & 8991 & 4496 & 4155 & 2078 & 8092 & 4046 & 2078 & PT \\
\hline & \multirow{4}{*}{$\begin{array}{c}\text { Strap } \\
2\end{array}$} & 1 & 2260 & 2317 & 1158 & 3648 & 1824 & 1385 & 693 & 3283 & 1642 & 693 & PT \\
\hline & & 2 & 4120 & 4633 & 2317 & 7296 & 3648 & 2770 & 1385 & 6566 & 3283 & 1385 & PT \\
\hline & & 3 & 5600 & 6950 & 3475 & 10944 & 5472 & 4155 & 2078 & 9849 & 4925 & 2078 & PT \\
\hline & & 4 & 6260 & 9267 & 4633 & 14591 & 7296 & 5540 & 2770 & 13132 & 6566 & 2770 & PT \\
\hline & \multirow{3}{*}{\begin{tabular}{|c} 
Strap \\
4
\end{tabular}} & 4 & 8440 & 9267 & 4633 & 17165 & 8582 & 5540 & 2770 & 15448 & 7724 & 2770 & PT \\
\hline & & 5 & 9260 & 11584 & 5792 & 21456 & 10728 & 6926 & 3463 & 19310 & 9655 & 3463 & PT \\
\hline & & 6 & 10430 & 13900 & 6950 & 25747 & 12874 & 8311 & 4155 & 23172 & 11586 & 4155 & PT \\
\hline
\end{tabular}




\begin{tabular}{|c|c|c|c|c|c|c|c|c|c|c|c|c|c|}
\hline \multirow{12}{*}{\begin{tabular}{|c} 
\\
\\
CFS \\
Type \\
B \\
D \\
$0.75 \mathrm{~mm}$
\end{tabular}} & \multirow{3}{*}{$\begin{array}{c}\text { Strap } \\
1\end{array}$} & 1 & 3040 & 2345 & 1173 & 2714 & 1357 & 1802 & 901 & 2443 & 1221 & 901 & PT \\
\hline & & 2 & 5000 & 4690 & 2345 & 5429 & 2714 & 3605 & 1802 & 4886 & 2443 & 1802 & PT \\
\hline & & 3 & 5410 & 7036 & 3518 & 8143 & 4072 & 5407 & 2704 & 7329 & 3664 & 2704 & PT \\
\hline & \multirow{3}{*}{$\begin{array}{c}\text { Strap } \\
\mathbf{3}\end{array}$} & 1 & 2680 & 2589 & 1295 & 2997 & 1499 & 1802 & 901 & 2697 & 1349 & 901 & PT \\
\hline & & 2 & 5270 & 5179 & 2589 & 5994 & 2997 & 3605 & 1802 & 5395 & 2697 & 1802 & PT \\
\hline & & 3 & 5440 & 7768 & 3884 & 8991 & 4496 & 5407 & 2704 & 8092 & 4046 & 2704 & PT \\
\hline & \multirow{3}{*}{$\begin{array}{c}\text { Strap } \\
2\end{array}$} & 1 & 3130 & 3152 & 1576 & 3648 & 1824 & 1802 & 901 & 3283 & 1642 & 901 & PT \\
\hline & & 2 & 5020 & 6303 & 3152 & 7296 & 3648 & 3605 & 1802 & 6566 & 3283 & 1802 & PT \\
\hline & & 3 & 6440 & 9455 & 4728 & 10944 & 5472 & 5407 & 2704 & 9849 & 4925 & 2704 & PT \\
\hline & \multirow{3}{*}{$\begin{array}{c}\text { Strap } \\
4\end{array}$} & 2 & 5140 & 7041 & 3520 & 8582 & 4291 & 3605 & 1802 & 7724 & 3862 & 1802 & PT \\
\hline & & 3 & 7380 & 10561 & 5280 & 12874 & 6437 & 5407 & 2704 & 11586 & 5793 & 2704 & PT \\
\hline & & 4 & 10140 & 14081 & 7041 & 17165 & 8582 & 7209 & 3605 & 15448 & 7724 & 3605 & PT \\
\hline
\end{tabular}

Table 10. Strap Bracing Experimental Capacities Compared to Design Capacities from Eurocode3 [24] (N)

\begin{tabular}{|c|c|c|c|c|c|c|c|c|c|c|c|c|c|c|c|}
\hline & & \multirow{3}{*}{$\begin{array}{l}\text { Screws } \\
\text { number }\end{array}$} & \multirow{3}{*}{$\begin{array}{c}\text { Pu } \\
\text { Monotonic } \\
\text { Tests }\end{array}$} & \multirow{2}{*}{\multicolumn{2}{|c|}{$\begin{array}{c}\text { Net-Section } \\
\text { Tension } \\
\text { Failure } \\
\end{array}$}} & \multirow{2}{*}{\multicolumn{2}{|c|}{$\begin{array}{l}\text { Bearing } \\
\text { Failure }\end{array}$}} & \multirow{2}{*}{\multicolumn{2}{|c|}{ Pull-out }} & \multicolumn{4}{|c|}{ Pull-over } & \multirow{3}{*}{\begin{tabular}{|c|} 
Limiting \\
Design \\
Capacity \\
(not including \\
cyclic \\
pullover) \\
\end{tabular}} & \multirow{3}{*}{$\begin{array}{c}\text { Related } \\
\text { Failure } \\
\text { Mode }\end{array}$} \\
\hline & & & & & & & & & & \multicolumn{2}{|c|}{ Static } & \multicolumn{2}{|c|}{ Cyclic } & & \\
\hline & & & & $\mathbf{N}_{t}$ & $\phi N_{t}$ & $V_{b}$ & $\phi V_{b}$ & $\mathbf{N}_{\text {ou }}$ & $\phi \mathbf{N}_{\text {ou }}$ & Nov & $\phi \mathbf{N}_{\mathrm{ov}}$ & $\mathbf{N}_{\mathrm{ov}}$ & $\begin{array}{c}\phi \\
\mathbf{N}_{\mathrm{ov}}\end{array}$ & & \\
\hline \multirow{13}{*}{$\begin{array}{c}\text { CFS } \\
\text { Type A } \\
0.55 \mathrm{~mm}\end{array}$} & \multirow{3}{*}{$\begin{array}{c}\text { Strap } \\
1\end{array}$} & 1 & 1980 & 3764 & 3011 & 1824 & 1459 & \begin{tabular}{|l|l}
733 \\
\end{tabular} & 587 & 1629 & 1303 & 814 & 651 & 587 & PT \\
\hline & & 2 & 3820 & 3596 & 2877 & 3648 & 2919 & 1467 & 1173 & 1629 & 1303 & 814 & 651 & 1173 & PT \\
\hline & & 3 & 4860 & 3596 & 2877 & 5472 & 4378 & 2200 & 1760 & 1629 & 1303 & 814 & 651 & 1303 & PR \\
\hline & \multirow{3}{*}{$\begin{array}{c}\text { Strap } \\
3\end{array}$} & 1 & 2130 & 4176 & 3341 & 2014 & 1611 & \begin{tabular}{|l|l}
733 \\
\end{tabular} & 587 & 1798 & \begin{tabular}{|l|l}
1439 \\
\end{tabular} & 899 & \begin{tabular}{|l|l|}
719 \\
\end{tabular} & 587 & PT \\
\hline & & 2 & 3820 & 4185 & 3348 & 4028 & 3222 & $\mid 1467$ & 1173 & 1798 & \begin{tabular}{|l|l}
1439 \\
\end{tabular} & 899 & 719 & 1173 & PT \\
\hline & & 3 & 5260 & 4185 & 3348 & 6042 & 4834 & 2200 & 1760 & 1798 & \begin{tabular}{|l|l}
1439 \\
\end{tabular} & 899 & \begin{tabular}{|l|}
719 \\
\end{tabular} & 1439 & PR \\
\hline & \multirow{4}{*}{ Strap } & 1 & 2260 & \begin{tabular}{|l|l|} 
\\
\end{tabular} & 4805 & 2451 & 1961 & \begin{tabular}{|l}
733 \\
\end{tabular} & 587 & 2189 & 1751 & 1094 & 875 & 587 & PT \\
\hline & & 2 & 4120 & 6007 & 4805 & 4903 & 3922 & 1467 & 1173 & 2189 & 1751 & 1094 & 875 & 1173 & PT \\
\hline & & 3 & 5600 & 6007 & 4805 & 7354 & 5883 & 2200 & 1760 & 2189 & 1751 & 1094 & 875 & 1751 & PR \\
\hline & & 4 & 6260 & \begin{tabular}{|l|l|}
6007 \\
\end{tabular} & 4805 & 9805 & 7844 & 2933 & 2347 & 2189 & 1751 & 1094 & 875 & 1751 & PR \\
\hline & \multirow{3}{*}{$\begin{array}{c}\text { Strap } \\
4\end{array}$} & 4 & 8440 & 10099 & 8079 & 11535 & 9228 & 2933 & 2347 & 2575 & 2060 & 1287 & 1030 & 2060 & PR \\
\hline & & 5 & 9260 & 10099 & 8079 & 14418 & 11535 & 3666 & 2933 & 2575 & \begin{tabular}{|l|}
2060 \\
\end{tabular} & 1287 & 1030 & 2060 & PR \\
\hline & & 6 & 10430 & 10099 & 8079 & 17302 & 13842 & 4400 & 3520 & 2575 & 2060 & 1287 & 1030 & 2060 & PR \\
\hline \multirow{12}{*}{$\begin{array}{c}\text { CFS } \\
\text { Type } \\
\text { B } \\
0.75 \mathrm{~mm}\end{array}$} & \multirow{3}{*}{$\begin{array}{c}\text { Strap } \\
1\end{array}$} & 1 & 3040 & 3764 & 3011 & 1824 & 1459 & 954 & 763 & 1629 & 1303 & 814 & 651 & 763 & PT \\
\hline & & 2 & 5000 & 3596 & 2877 & 3648 & 2919 & 1908 & 1527 & 1629 & 1303 & 814 & 651 & 1303 & PR \\
\hline & & 3 & 5410 & 3596 & 2877 & 5472 & 4378 & 2863 & 2290 & 1629 & 1303 & 814 & 651 & 1303 & PR \\
\hline & \multirow{3}{*}{$\begin{array}{c}\text { Strap } \\
3\end{array}$} & 1 & 2680 & 4176 & 3341 & 2014 & 1611 & 954 & 763 & 1798 & 1439 & 899 & 719 & 763 & PT \\
\hline & & 2 & 5270 & 4185 & 3348 & 4028 & 3222 & 1908 & 1527 & 1798 & \begin{tabular}{|l}
1439 \\
\end{tabular} & 899 & \begin{tabular}{|l|l|}
719 \\
\end{tabular} & 1439 & PR \\
\hline & & 3 & 5440 & 4185 & 3348 & 6042 & 4834 & 2863 & 2290 & 1798 & \begin{tabular}{|l|l}
439 \\
\end{tabular} & 899 & 719 & 1439 & PR \\
\hline & \multirow{3}{*}{$\begin{array}{c}\text { Strap } \\
2\end{array}$} & 1 & 3130 & 6007 & 4805 & 2451 & 1961 & 954 & 763 & 2189 & \begin{tabular}{|l|l|} 
\\
\end{tabular} & 1094 & 875 & 763 & PT \\
\hline & & 2 & 5020 & 6007 & 4805 & 4903 & 3922 & 1908 & 1527 & 2189 & 1751 & 1094 & 875 & 1527 & PT \\
\hline & & 3 & 6440 & 6007 & 4805 & 7354 & 5883 & 2863 & 2290 & 2189 & 1751 & 1094 & 875 & 1751 & PR \\
\hline & \multirow{3}{*}{$\begin{array}{c}\text { Strap } \\
4\end{array}$} & 2 & 5140 & 10099 & 8079 & 5767 & 4614 & 1908 & 1527 & 2575 & 2060 & 1287 & 1030 & 1527 & PT \\
\hline & & 3 & 7380 & 10099 & 8079 & 8651 & 6921 & 2863 & 2290 & 2575 & 2060 & 1287 & 1030 & 2060 & PR \\
\hline & & 4 & 10140 & 10099 & 8079 & 11535 & 9228 & 3817 & 3053 & 2575 & 2060 & 1287 & 1030 & 2060 & PR \\
\hline
\end{tabular}

It is necessary to mention that all edge distance and spacing requirements of the standards were satisfied except for in the perforated straps where there pre-existing perforations governed screw arrangements. Although the screws did increase the size of the holes from $3 \mathrm{~mm}$ to $4.8 \mathrm{~mm}$, if the screws were not placed in the existing holes the net area would have been further reduced as there would be the pre-existing holes plus the additional screw holes. For the pattern of the pre-existing holes as was present in both of the perforated straps used for this study, there is no space to add holes for more than one individual screw where the extra holes will not decrease the net area of the strap and therefore weaken the strap. 
The result tables show that the test specimen capacities exceed the nominal design capacities for all three of the standards considered. For the design calculations in this paper, the bearing and tilting capacities calculated for all three standards were assumed to increase directly with number of screws. That is, a connection with three screws is calculated to have the bearing capacity of one screw multiplied by three. Although this assumption was made, it is known that this is unconservative; however a more accurate relationship is not known. The design bearing capacities calculated by AS/NZS4600 and AISI are the same for most specimens, and the only differences vary by less than $3 \%$ for the strap types 1 and 2 connected to the $0.75 \mathrm{~mm}$ cold-formed steel when AS/NZS includes a bearing capacity factor which applies to these specimens. Eurocode 3 is less conservative and predicts significantly higher values (more than 50\%) for factored bearing capacity. It is difficult to compare the design capacities with the experimental failure loads for this mode of failure as although many specimens exhibited bearing and tilting, it was never the ultimate failure mode. This makes hard to determine the load at which bearing first occurred. AS/NZS4600 and the AISI Specification specified factored bearing capacities for many of the tested specimens that were below the ultimate load capacity of the specimen. This is a true indication of the bearing and tilting behavior that had occurred in the specimens. The higher bearing values from Eurocode 3 exceed the ultimate loads for some specimens which prove the standard is highly unconservative when predicting this type of failure mode capacity.

Similarly for pull-out and pull-over failures, a direct relationship was assumed between the number of screws and the design resistance to these failure modes. This also assumes the load is distributed evenly among the screws. The pull-over provisions are included from all three standards, however as there was only one case of pull-over which occurred in all of the monotonic and cyclic specimens tested, this design capacities as calculated for this failure mode are not discussed in detail here. For AS/NZS4600 and the AISI Specification the pull-over and pull-out capacities are calculated using the same equations and for the connections considered in this study, pull-out is the governing design capacity of the two for all cases. This is a true indication of the pull-out failures which occurred in most connections with insufficient screws for net section failure to occur. Eurocode3 conversely predicts more similar pull-over values as a result of its provisions' dependence on the pitch of the screw threads. Consequently, Table 10 shows that this standard often predicts that pull-over is the governing failure mode for the connections, which is inaccurate.

For net section tension failure, the unfactored capacities will be compared here but it should be noted that the AS/NZS4600 reduction factor of 0.65 is significantly more conservative than Eurocode3's factor of 0.8 . The unfactored net section capacities predicted by AS/NZS4600 are reduced for single screwed connections, but for the remaining multiple screw connections, the capacities are the same as those given by Eurocode3. For the solid straps the standards accurately predict unfactored net section failure capacities which are greater than the ultimate capacities for the specimens which failed by eventual pull-out, and only slightly less than ultimate capacities which did fail by net section failure. The predicted capacities for the perforated straps are less accurate, particularly for the specimens which had two screws which was one less than the three required for net section failure to occur in all perforated strap specimens. The inaccuracy of these predictions can be attributed to the variable net section of the perforated straps.

Although these design provisions have some value in predicting some of the behaviors for screwed connections, there are some provisions which are not entirely suited to accurately predicting the ultimate behavior of the strap bracing connections tested for this research. Hancock [6] states that 'the provisions are intended for use when a sufficient number of test results is not available for the particular application, (and that) a higher degree of accuracy can be obtained by testing any particular application'. Therefore the recommended capacities for the strap bracing connections will be based on the experimental results. 
As discussed earlier, the pattern of the screws was chosen in order to obtain satisfy the requirements of AS4100 provisions for the net section tension capacity of a member as best as possible with the given straps sizes and screw dimensions, but different patterns were not tested to completely optimize this design. This pattern selection was not further optimized because it was proven in by LaBoube and Sokol [19] that the effect of optimizing the pattern is very small in increasing the strength of the connection.

\section{CONCLUSIONS AND RECOMMENDATIONS}

The capacities of the screwed strap bracing connections are taken as the monotonic capacities found for each connection. These capacities were compared to the cyclic capacities of each connection and it was found that in general the cyclic capacities were higher than the monotonic values. Therefore it is a conservative approach to design wall bracing systems to the monotonic capacities. The required number of screws to obtain the maximum capacity of the strap materials, and the value of the ultimate load capacity of each connection based on monotonic tests are summarized in Table 11.

Table 11- Number of screws required, and the capacity of the connections for each type of strap bracing material based on monotonic tests

\begin{tabular}{|c|c|c|c|c|}
\hline $\begin{array}{l}\text { CFS } \\
\text { Type }\end{array}$ & Strap Type & $\begin{array}{l}\text { Number of } \\
\text { Screws } \\
\text { Required }\end{array}$ & $\underset{(\mathrm{kN})}{\mathbf{P}_{\mathrm{u}}}$ & $\begin{array}{c}\Delta_{\mathbf{u}} \\
(\mathbf{m m})\end{array}$ \\
\hline \multirow{4}{*}{$\begin{array}{l}\text { Type A } \\
0.55 \mathrm{~mm}\end{array}$} & $\begin{array}{c}\text { Strap 1 } \\
\text { G3 Perforated } \\
30 \mathrm{~mm} * 0.75 \mathrm{~mm} \\
\end{array}$ & 3 & 4.86 & 6.9 \\
\hline & $\begin{array}{c}\text { Strap 3 } \\
\text { G2 Perforated } \\
30 \mathrm{~mm}^{*} 0.75 \mathrm{~mm} \\
\end{array}$ & 3 & 5.26 & 11.6 \\
\hline & $\begin{array}{c}\text { Strap 2 } \\
\text { G2 Solid 30mm*0.75mm }\end{array}$ & 4 & 6.26 & 17.5 \\
\hline & $\begin{array}{c}\text { Strap } 4 \\
\text { G2 Solid 40mm*1.0mm } \\
\end{array}$ & 6 & 10.43 & 27.9 \\
\hline \multirow{4}{*}{$\begin{array}{l}\text { Type B } \\
0.75 \mathrm{~mm}\end{array}$} & $\begin{array}{c}\text { Strap 1 } \\
\text { G3 Perforated } \\
30 \mathrm{~mm} * 0.75 \mathrm{~mm} \\
\end{array}$ & 3 & 5.41 & 6.9 \\
\hline & $\begin{array}{c}\text { Strap 3 } \\
\text { G2 Perforated } \\
\text { 30mm*0.75mm }\end{array}$ & 3 & 5.44 & 7.1 \\
\hline & $\begin{array}{c}\text { Strap 2 } \\
\text { G2 Solid } 30 \mathrm{~mm}^{*} 0.75 \mathrm{~mm}\end{array}$ & 3 & 6.44 & 11 \\
\hline & $\begin{array}{c}\text { Strap } 4 \\
\text { G2 Solid 40mm*1.0mm }\end{array}$ & 4 & 10.14 & 10.7 \\
\hline
\end{tabular}

According to the current research results, following conclusions can be made:

- The $0.75 \mathrm{~mm}$ cold-formed steel increased the capacity of the strap bracing connections by $3-11 \%$ more than the $0.55 \mathrm{~mm}$ cold-formed steel for the straps types 1,2 and 3 , due to the increased anchorage of the connection. The slight reduction in capacity of the type 4 strap can be attributed to the fewer screws used in the connections to $0.75 \mathrm{~mm}$ cold-formed steel.

- For both the $0.75 \mathrm{~mm}$ and the $0.55 \mathrm{~mm}$ cold-formed steel connections the extension of the straps at ultimate strength was significantly higher for the type 2 solid strap material than both of the perforated strap materials. 
- $\quad$ Of the two perforated strap materials which had the same dimensions: the type 3 G2 strap would be recommended for use rather than type $1 \mathrm{G} 3$ strap due to its increased capacity and ductility.

- In comparison to the perforated straps the solid strap type 2 exhibited capacities which were higher than those of the type 3 perforated straps when connected to both thicknesses of cold formed steel. The type 2 strap also demonstrated greater extensions than the perforated straps at ultimate load.

- $\quad$ The type 4 solid strap fastened with the maximum numbers of screws had significantly higher capacities than the type 2 solid strap due to its greater cross-sectional area. The type 4 straps demonstrated significantly higher extension at ultimate load in the $0.55 \mathrm{~mm}$ cold-formed steel than of the type 2 solid strap, and similar extension in the $0.75 \mathrm{~mm}$ cold-formed steel. The lower extension of the type 4 strap connected to the $0.75 \mathrm{~mm}$ cold-formed steel can be attributed to the lower number of screws used in this connection.

- Another strap type which would be worth consideration is solid G3 strap material. Although the perforated G3 strap (type 1) had less capacity than the perforated G2 strap, the strength properties of the G3 sheet material indicate that it is expected to have significantly different yield and ultimate strengths, which may result in more ductile behaviour than was exhibited by the solid G2 strap in this research as the G2 material has very similar yield and ultimate strengths. The perforations in the G3 strap tested for this study would have significantly affected the performance of the material, particularly in relation to the ultimate capacity of the material due to the reduction in net cross-sectional area. Therefore it is recommended that solid G3 strap material be tested and compared to the materials tested in this paper.

- The application of these particular strap types for the bracing systems will depend on the required capacity and ductility of the system. The solid straps exhibited higher extensions before their ultimate failure than the perforated straps, and therefore they may be preferred in areas where there is the potential for significant cyclonic or seismic events which may impose large deflections on the wall framing system.

- $\quad$ The limited area for the strap to be connected to the wall framing system may mean that it is not practical to use the number of screws recommended here. This could be a particular problem when using the thicker and wider type 4 strap material with $0.55 \mathrm{~mm}$ cold-formed steel framing, as it requires 6 screws for adequate anchorage of the strap. Further investigation is recommended in order to quantify the maximum available area to which the straps can be fastened, and therefore the maximum number of screws which can be used to anchor the straps and satisfy the minimum edge and spacing requirements specified by AS/NZS4600.

\section{REFERENCES}

[1] Kim, T.-W., Wilcoski, J., Foutch, D.A. and Lee, M.S., "Shake Table Tests of a Cold-formed Steel Shear Panel”, Engineering Structures, 2006, Vol. 28, pp. 1462-1470.

[2] Moghimi, H. and Ronagh, H.R., "Performance of Light-gauge Cold-formed Steel Strap-braced Stud Walls subjected to Cyclic Loading", Engineering Structures, 2009, Vol. 31, pp. 69-83.

[3] Zeynalian, M. and Ronagh, H., "Experimental Study on Seismic Performance of Strap-braced Cold-formed Steel Shear Walls", Advances in Structural Engineering, 2013, Vol. 16, pp. 245-257.

[4] Zeynalian, M. and Ronagh, H.R., "A Numerical Study on Seismic Performance of Strap-braced Cold-formed Steel Shear Walls", Thin-Walled Structures, 2012, Vol. 60, pp. 229-238.

[5] Yu, W.-W. and LaBoube, R.A., "Cold-formed Steel Design”, John Wiley \& Sons, 2010. 
[6] Hancock, G.J., Murray, T. and Ellifrit, D.S., "Cold-formed Steel Structures to the AISI Specification", CRC Press, 2001.

[7] Hancock, G.J., "Design of Cold-formed Steel Structures: To Australian/New Zealand Standard AS/NZS 4600", Australian Institute of Steel Construction, 1998.

[8] Rogers, C.A. and Hancock, G.J., "Screwed Connection Tests of Thin G550 and G300 Sheet Steels", Journal of Structural Engineering, 1999, Vol. 125, pp. 128.

[9] AS/NZS4600, "Cold-formed Steel Structures", Australian Building Codes Board, 2005.

[10] Adham, S.A., Avanessian, V., Hart, G.C., Anderson, R., Elmlinger, W.J. and Gregory, J., "Shear Wall Resistance of Lightgauge Steel Stud Wall Systems", Earthquake Spectra, 1990, Vol. 6, pp. 1-14.

[11] Hatami, S., Ronagh, H. and Ashari, M., "Behavior of Thin-strap-braced Cold-formed Steel Frames under Cyclic Loads", Proceedings of Fifth International Conference on Thin-Walled Structures, Queensland University of Technology, 2008, pp. 363-370.

[12] Fiorino, L., Della Corte, G. and Landolfo, R., "Experimental Tests on Typical Screw Connections for Cold-formed Steel Housing”, Engineering Structures, 2007, Vol. 29, pp. 1761-1773.

[13] Lennon, R., Pedreschi, R. and Sinha, B., "Comparative Study of Some Mechanical Connections in Cold Formed Steel”, Construction and Building Materials, 1999, Vol. 13, pp. 109-116.

[14] Peterman, K.D., Nakata, N. and Schafer, B.W., "Hysteretic Characterization of Cold-formed Steel Stud-to-sheathing Connections", Journal of Constructional Steel Research, 2014, Vol. 101 pp. 254-264.

[15] Buildex Co., "Self-Drilling Screws, Fasteners \& Rivets", 2006, Victoria, Australia.

[16] Quickframe Steel Frames Pty Ltd, "Steel Frame Fixing Manual”, 2007, Australia.

[17] BlueScope Co., "Complete Distribution Product Guide, Version 3", 2009, Australia.

[18] AS/NZS4100, "Steel Structure, AS/NZS 4100", Australian Building Codes Board, 2012.

[19] LaBoube, R. and Sokol, M., "Behavior of Screw Connections in Residential Construction", Journal of Structural Engineering, 2002, Vol. 128, pp. 115-118.

[20] Zeynalian, M. and Ronagh, H.R. "An Experimental Investigation on the Lateral Behavior of Knee-braced Cold-formed Steel Shear Walls”, Thin-Walled Structures, 2012, Vol. 51, pp. 64-75.

[21] Zeynalian, M., Shelley, A. and Ronagh, H.R., "An Experimental Study into the Capacity of Cold-formed Steel Truss Connections”, Journal of Constructional Steel Research, 2016, Vol. 127 pp. 176-186.

[22] ASTM-E2126-07, "Standard Test Methods for Cyclic (reversed) Load Test for Shear Resistance of Walls for Buildings", 2007,USA.

[23] AISI, "North American specification for the Design of Cold-formed Steel Structural Members", American Iron and Steel Institute, 2012, Washington, D.C.

[24] Eurocode3, "Design of Steel Structures. Part 1-3, General Rules - Supplementary Rules for Cold-formed Members and Sheeting", European Committee for Standardization, 2001, Dublin. 